\title{
Cellular Basis of EEG Slow Rhythms: A Study of Dynamic Corticothalamic Relationships
}

\author{
D. Contreras and M. Steriade
}

Laboratoire de Neurophysiologie, Faculté de Médecine, Université Laval, Quebec, Canada G1K 7P4

\begin{abstract}
A slow oscillation $(<1 \mathrm{~Hz}$ ) has recently been described in intracellular recordings from the neocortex and thalamus (Steriade et al., 1993c-e). The aim of the present study was to determine the phase relations between cortical and thalamic neuronal activities during the slow EEG oscillation. Intracellular recordings were performed in anesthetized cats from neurons in motor and somatosensory cortical areas, the rostrolateral sector of the reticular (RE) thalamic nucleus, and thalamocortical (TC) cells from ventrolateral (VL) nucleus. The EEG was used as time reference for alignment of activities in different, simultaneously recorded neurons, including dual impalements of cortical cells as well as cortical and TC cells.
\end{abstract}

The spontaneous EEG oscillation was characterized by slowly recurring $(0.3-0.9 \mathrm{~Hz})$ sequences of surface-positive (depth-negative) sharp deflections, often followed by oscillatory activity within the frequency range of sleep spindles $(7-14 \mathrm{~Hz})$ or at faster frequencies. Cortical and RE cells were similarly hyperpolarized during the depth-positive EEG waves and were depolarized during the depth-negative EEG deflections. In many instances, the cell depolarization was associated with oscillations at the spindle frequency or with tonic firing at rates related to the level of depolarization. TC neurons were hyperpolarized during the depth-positive EEG waves and displayed a series of IPSPs, at the spindle frequencies, during the depth-negative EEG waves. Depending on the membrane potential $\left(V_{m}\right)$, TC cells could fire spike bursts at the onset of the EEG depth-negativity, or their firing could be delayed by subsequent IPSPs. The sequence of spontaneous EEG and cellular events described above also characterized the responses to cortical and thalamic stimulation. Simultaneous intracellular recordings of pairs of cortical cells or cortical and TC cells showed that spontaneous transitions from less synchronized to more synchronized EEG states were marked by a simultaneous hyperpolarization, coincident with an overt depth-positive EEG wave.

We conclude that during low-frequency oscillatory states, characteristic of slow-wave sleep, neocortical and thalamic neurons display phase relations that are restricted to narrow time windows, and that synchronization results from a gen-

\footnotetext{
Received Apr. 13, 1994; revised June 22, 1994; accepted July 1, 1994.

This work was supported by the Medical Research Council of Canada (Grant MT-3689). We thank G. Oakson for analysis software, P. Giguère and D. Drolet for technical assistance, and D. Paré for helpful discussions. D.C. is a doctoral student partially supported by a fellowship from the Savoy Foundation.

Correspondence should be addressed to Professor Dr. M. Steriade at the above address.

Copyright (C) 1995 Society for Neuroscience $0270-6474 / 95 / 150604-19 \$ 05.00 / 0$
}

eralized inhibitory phenomenon. Moreover, EEG synchronization is reflected as active inhibition in TC neurons. That this pattern is also present in states of hypersynchronization, such as seizure activity, is shown in the following paper (Steriade and Contreras, 1994).

[Key words: slow oscillations, spindling, cortex, reticular thalamic, thalamocortical, inhibition]

Rhythmic oscillations are a common behavior of many neural systems. Rhythmicity may arise as the result of activity in pacemaker cells endowed with intrinsic oscillatory activity and connected to a population with particular resonant characteristics. Alternatively, rhythmic patterns may emerge from cellular interactions within a network, even if none of the constituent elements is capable of autorhythmicity. These two propositions have to be eclectically considered, as the shape and frequencies of brain oscillations depend on both neuronal autorhythmicity (Bremer, 1949; Llinás, 1988) and synaptic bombardment from network operations (Steriade et al., 1990, 1993b).

Population oscillations in the cerebral cortex and thalamus are reflected as rhythmic waves in the electroencephalogram (EEG). The spontaneous EEG activity represents the statistical aspect of the continuously fluctuating condition of the brain (Bremer, 1958). It was proposed that such oscillations reflect correlated synaptic activity in cortical cells (Klee et al., 1965; Creutzfeldt et al., 1966a,b), as the ionic currents involved in the generation of fast action potentials may not contribute greatly to the averaged field potentials representing the EEG. Although EEG rhythms display dramatic alterations during various states of vigilance, little is known about the dynamic relations between cellular activities in the cortex and thalamus during the transition to the low-frequency synchronized oscillations that characterize the state of quiescent (resting) sleep. The goal of the present work was to study the phase relations between cortical and thalamic neurons during a slow $(<1 \mathrm{~Hz})$ sleep oscillatory state (Steriade et al., 1993c-e) using multisite recordings, including dual impalements of cortical cells as well as cortical and thalamocortical (TC) cells.

The state of sleep is dominated by three major types of brain rhythms: spindles $(7-14 \mathrm{~Hz})$ occurring prevalently during early stages, $\delta$ waves $(1-4 \mathrm{~Hz})$ appearing during later stages of sleep, and slow $(<1 \mathrm{~Hz})$ oscillations that are present throughout resting sleep (see Steriade, 1993). It was demonstrated that thalamic spindles survive in decorticated and brainstem-transected animals (Morison and Bassett, 1945) and that the reticular thalamic (RE) nucleus plays a pivotal role in their genesis and synchronization (Steriade et al., 1985, 1987). The $\delta$ rhythm consists of at least two components. The cortical one is present after thalamectomy (Villablanca, 1974; Steriade et al., 1993d), but as yet 
has not been investigated intracellularly. The second component is due to the capacity of TC cells, recorded from distantly located and functionally different thalamic nuclei, to generate an intrinsic oscillation within the $\delta$ frequency range through the interplay between two of their voltage-gated currents (McCormick and Pape, 1990; Leresche et al., 1991; Steriade et al., 1991; Curro Dossi et al., 1992). The $\delta$-oscillating single TC cells can be synchronized by corticothalamic volleys, presumably by driving inhibitory RE neurons (Steriade et al., 1991). The slow cortical rhythm was described in intracellular recordings from a variety of sensory, motor, and associational areas, even after extensive thalamic lesions (Steriade et al., 1993c,d). It was postulated that the cortical slow rhythm groups the thalamically generated (spindle and $\delta$ ) oscillations within slowly recurring wave sequences (Stcriade ct al., 1993e).

Although the above studies provided significant data related to the oscillatory behavior of cortical, RE, and TC cells, a detailed analysis of dynamic relations between simultaneously recorded cortical and thalamic neurons during low-frequency oscillatory states was lacking. The present paper is aimed at analyzing the membrane fluctuations of cortical and thalamic cells with respect to the major components of the sleep EEG, and determining the temporal relations between intracellularly recorded activities of these neurons during the slow and spindle rhythms.

\section{Materials and Methods}

Experiments were carried out on 56 adult cats $(2.5-3.5 \mathrm{~kg})$ anesthetized with ketamine-xylazine $(10-15 \mathrm{mg} / \mathrm{kg} ; 2-3 \mathrm{mg} / \mathrm{kg}$, i.m.). Animals were paralyzed with gallamine triethiodide and artificially ventilated. Endtidal $\mathrm{CO}_{2}(3.5-3.7 \%)$ and heart rate were continuously monitored. Body temperature was maintained at $37-39^{\circ} \mathrm{C}$. The depth of the anesthesia was maintained by additional doses of the same anesthetic in order to keep a constant picture of high-amplitude low-frequency waves in the EEG.

For cortical intracellular recordings the surface of the pericruciate areas was exposed, after resection of the overlying bone and dura, and bathed in mineral oil to prevent desiccation.

For thalamic intracellular recordings the surface of the cortex that corresponds to the anterior half of the marginal and suprasylvian gyri was cauterized with silver nitrate. The cortex and white matter were removed by suction until exposing the head of the caudate nucleus. Micropipettes were then lowered through the head of the caudate in order to reach the rostrolateral sector of the RE nucleus and the ventrolateral (VL) thalamic nucleus.

The stability of the recordings was improved by performing a bilateral pneumothorax, as well as by the drainage of the cisterna magna, hip suspension, and filling the holes made for recording with a solution of $4 \%$ agar. All wounds and pressure points were infiltrated with lidocaine.

Recording and stimulation. Gross EEG was recorded monopolarly by means of a screw inserted into the bone, over the pericruciatc area of the cortex contralateral to the side of cellular recordings. The focal EEG was recorded by means of coaxial electrodes with exposed areas of 0.2 $\mathrm{mm}$ separated by $0.6 \mathrm{~mm}$. The EEG recording electrodes were placed, according to the system under study, in the lateral part of the precruciate gyrus (motor cortex, area 4 ) or in the region of the postcruciate gyrus representing the right forepaw (somatosensory cortex, area $3 \mathrm{~b}, 1$ and 2); the depth was adjusted to obtain an inverse polarity of the thalamically evoked potential. Another coaxial electrode was used to record the EEG in the contralateral motor cortex when performing simultaneous intracellular recordings from both hemispheres. In all monopolar recordings the indifferent electrode was placed in the neck muscles.

Stimulating coaxial electrodes were placed in the VL nucleus, when studying the motor system, or in the ventroposterior (VP) nucleus and in the dorsal column nuclei (DCN), when studying the somatosensory system, according to conventional stereotaxic coordinates. Stimulation was also performed by means of the coaxial electrodes used for EEG recording, or a coaxial electrode inserted in the internal capsule.

Intracellular recordings were performed with glass micropipettes filled with a solution of $2 \mathrm{M}$ potassium acetate and $2 \%$ Neurobiotin (Vector Laboratories), and DC resistances of 35-45 M 2 . The pipettes for intracellular recordings in the cortex were placed at around $1 \mathrm{~mm}$ apart from the coaxial EEG recording electrodes. The depth of the pipettes was read on the scale of the micromanipulator. A high-impedance amplifier (bandpass of $0-5 \mathrm{kHz}$ ) with active bridge circuitry was used to record and inject current into the cells. Extracellular recordings were done by means of tungsten electrodes with resistances of 1-5 M $\Omega$. The signals were recorded on an eight-channel tape with a bandpass of $0-9 \mathrm{kHz}$, posteriorly digitized at $20 \mathrm{kHz}$ for off-line computer analysis.

Histology. Upon termination of the experiment, the deeply anesthetized animals were perfused transcardially with physiological saline followed by $10 \%$ paraformaldehyde. The brain was removed and stored in formalin with $30 \%$ sucrose. When the brain sank, it was sectioned at $80 \mu \mathrm{m}$, processed with the avidin-biotin standard kit (ABC standard kit, Vector Laboratories), mounted on gel-dipped slides, and coverslipped.

\section{Results}

\section{Data base and neuronal identification}

The results are based on 190 cortical cells, 223 RE neurons, and 116 TC neurons. Cortical cells were recorded from the motor cortex ( $n=74$, intra; $n=20$, extra) and the primary somatosensory cortex ( $n=51$, intra; $n=45$, extra). RE cells were recorded intra- $(n=70)$ and extracellularly $(n=102)$ from the rostral pole and peri-VL sector of the RE nucleus, and extracellularly $(n=51)$ from the region lateral to the VP complex. TC neurons were recorded both intra- $(n=26)$ and extracellularly $(n=36)$ from the VL nucleus and extracellularly $(n=$ 54) from VP. The recordings that were used for the data base and analyses had stable membrane potentials $\left(V_{m}\right)$ more negative than $-55 \mathrm{mV}$ for at least $15 \mathrm{~min}$, and overshooting action potentials.

Cortical cells recorded intracellularly were classified, according to previous in vitro (McCormick et al., 1985) and in vivo (Nuñez et al., 1993) studies, as regular spiking $(78 \%, n=98)$, intrinsically bursting $(18 \%, n=22)$, or fast spiking $(4 \%, n=5)$. They were located in layers $2-6$ as estimated by reading the microdrive position display. This estimation of neuronal depth had an error of less than $15 \%$ when compared to the position of neurons intracellularly stained with Neurobiotin $(n=16)$. In a representative sample of 55 cortical cells, the resting membrane potential was $-71 \pm 1.6 \mathrm{mV}$ (mean $\pm \mathrm{SE}$ ), the amplitude of the action potentials was $79 \pm 1.2 \mathrm{mV}$, and the input resistance was $22.5 \pm 2.1 \mathrm{M} \Omega$ (estimated by applying square hyperpolarizing current pulses at the resting $V_{m}$ ). Motor cortical cells responded with an excitatory postsynaptic potential (EPSP) to electrical stimulation of the VL nucleus, with latencies of 1$4 \mathrm{msec}$ (see Fig. 3). Cells from the somatosensory cortex belonged to the region of the right forepaw, as they responded with robust excitatory potentials to tapping of that body region. They displayed EPSPs in response to stimulation of $V P$ with latencies of $1-4 \mathrm{msec}$, and to DCN stimulation with latencies of 5-8 msec.

Neurons from the RE nucleus had $V_{\mathrm{ms}}$ of $-63.8 \pm 1.8 \mathrm{mV}$ and an input resistance of $37.6 \pm 1.6 \mathrm{M} \Omega$. Action potentials had an amplitude of $69 \pm 1 \mathrm{mV}$ and a duration at the base of $0.9 \pm 0.3 \mathrm{msec}$. RE neurons displayed an important inward rectification and no signs of the slow inward rectifier $I_{h}$ (Contreras et al., 1993). They were identified by a characteristic response to cortical or dorsal thalamic stimulation, consisting of an initial high-frequency burst of 4-8 spikes, followed by a sequence of depolarizing waves within the frequency range of spindle oscillations (see Fig. 4, Evoked). RE neurons recorded 


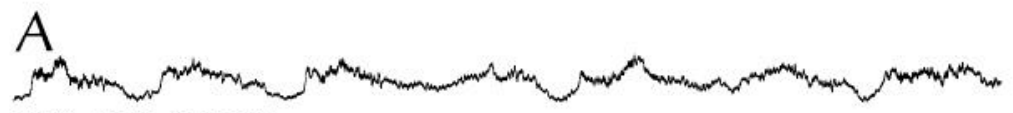

EEG-surf. area $3 b$



EEG-depth area $3 b$
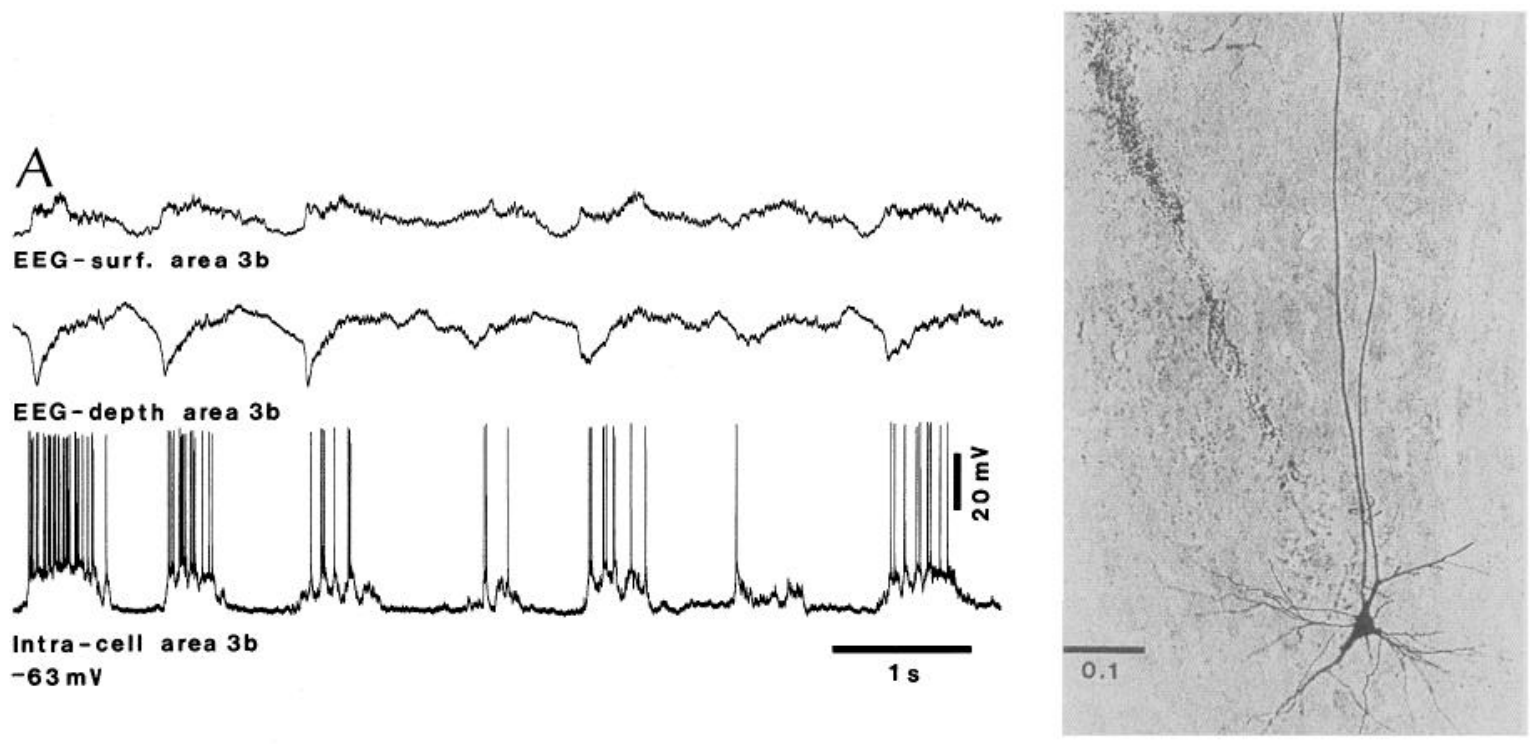

B

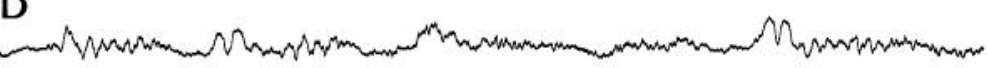

EEG-surf. area $3 b$


EEG-depth area $3 \mathbf{b}$
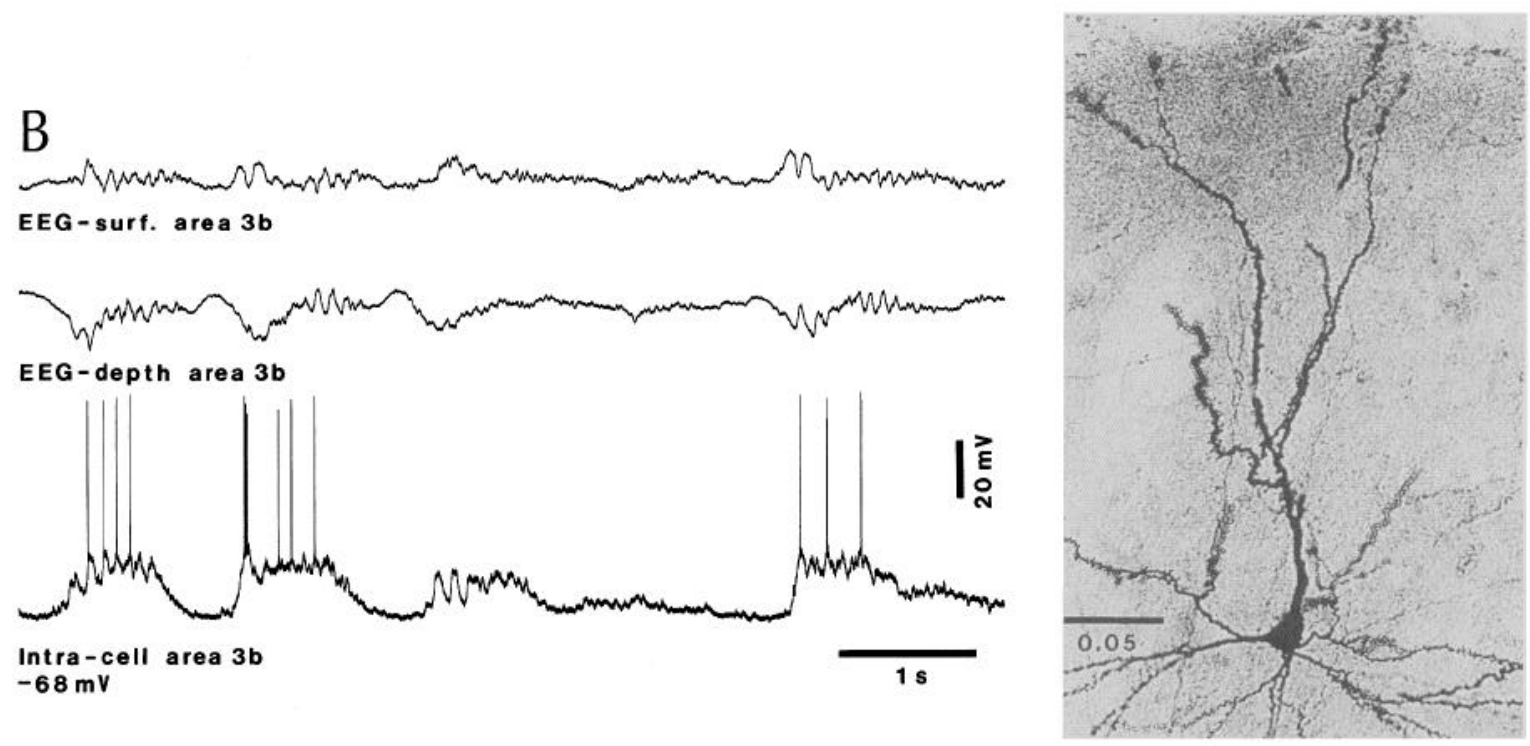

C

CEM EEG-surf. are a 4 EEG-depth area 4

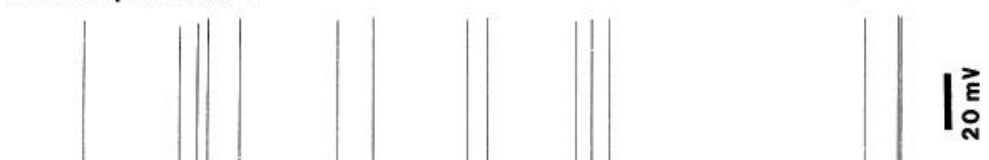


Intra-cell area 4 $-70 \mathrm{mv}$
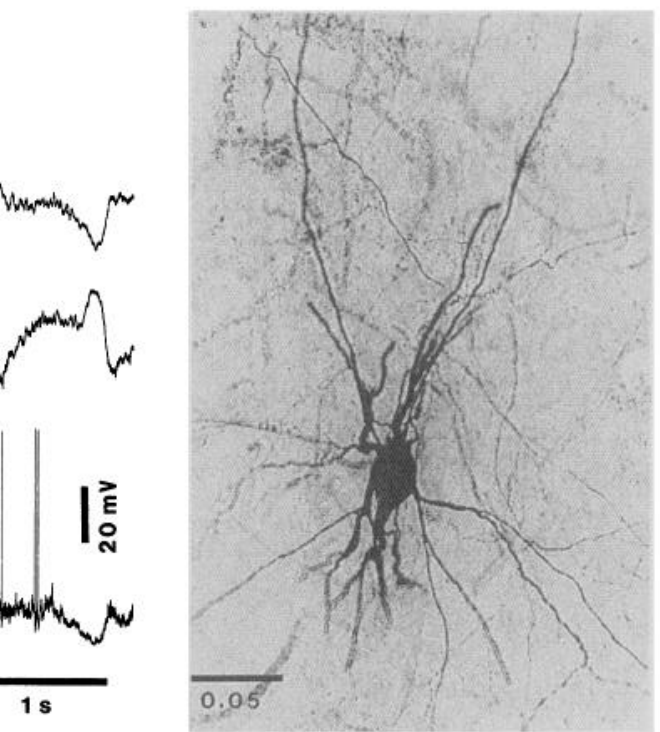
extracellularly were identified by their accelerating-decelerating bursting pattern (Domich et al., 1986). Neurons recorded from the peri-VP sector responded, probably bisynaptically, to tapping their receptive fields or DCN stimulation.

TC cells from the VL nucleus had $V_{\mathrm{ms}}$ of $-62.3 \pm 1.5 \mathrm{mV}$, input resistances of $18.3 \pm 1.1 \mathrm{M} \Omega$, and action potential amplitude and duration (at the base) of $64.2 \pm 1.4 \mathrm{mV}$ and $1.1 \pm$ $0.3 \mathrm{msec}$, respectively. They were identified by antidromic invasion and EPSPs in response to motor cortex stimulation, followed by a sequence of IPSPs at the spindling frequency, occasionally giving rise to rebound spike bursts. TC cells recorded extracellularly were identified by high-frequency spike bursts with two or three spikes in a decelerating pattern in response to motor cortex stimulation (VL cells) or tapping on the receptive field or stimulating the DCN (VP cells). To confirm their location, some VL cells $(n=5)$ were intracellularly stained with Neurobiotin (see Fig. 7).

\section{Cortical cells}

Motor cortical cells displayed oscillatory patterns and relations to focal EEG activity similar to those in the somatosensory cortex. Therefore, they will be considered together. Under the anesthetic conditions described in Materials and Methods, cortical cells spontaneously displayed a sustained slow oscillation with a frequency ranging between 0.3 and $0.9 \mathrm{~Hz}$, as described recently (Steriade et al., 1993c). As reported in that previous paper, cortical neurons recorded under ketamine and xylazine anesthesia displayed slow oscillations at higher frequencies $(0.6-$ $0.9 \mathrm{~Hz}$ ) than under urethane anesthesia (mostly at $0.3-0.5 \mathrm{~Hz}$ ). The oscillation consisted of depolarizing plateaus interrupted by long-lasting hyperpolarizing periods that lasted for $0.2-0.8$ sec (Figs. 1, 2). Cellular events were clearly correlated to the EEG recorded at $\sim 1 \mathrm{~mm}$ from the cell: a surface-negative (depthpositive) potential was coincident with the cellular hyperpolarization, followed by a surface-positive (depth-negative) wave that was related to the cellular depolarization (Figs. 1, 2).

At the level of the EEG, the major events characterizing the slow oscillation were the long-lasting depth-positive wave and the first sharp depth-negative deflection in each cycle. These components consistently showed reversed polarities between the depth and the surface. Following the initial depth-negative deflection, different oscillatory patterns were often distinguishable in the EEG and were reflected in the depolarizing phase of the cellular oscillation. These were $7-14 \mathrm{~Hz}$ spindle oscillations (Fig. $1 B$ ) or rhythms with faster frequencies (Fig. $1 C$ ).

Pyramidal neurons from deep (Fig. 1A) or superficial (Fig. $1 B$ ) layers oscillated with a similar relation of phase to the $E E G$ waves, indicating that the inhibitory and excitatory events that underlie the slow oscillation occurred synchronously throughout the depth of the cortical mantle. The inversion of polarity of the major components of the EEG was obtained from the depth electrode $(\sim 0.6 \mathrm{~mm})$ and the surface one. Moreover, as seen in the EEG traces of Figure 1, the depth EEG (at $0.6 \mathrm{~mm}$ ) was constant in its relation with the cells and had an amplitude that was equivalent or higher than the EEG recorded from the surface. These data suggest a simple sink-source arrangement for the major depolarizing and hyperpolarizing events of the oscillation, in which a common source or sink, respectively, would be located very superficially, probably represented by the apical dendrites of pyramidal cells that ramify in layer I. The oscillatory patterns that followed the initial depth-negative sharp deflection did not show a consistent picture of inverse polarities between the depth and the surface, suggesting more complex dipolar arrangements.

No difference was observed between various electrophysiological types of pyramidal cells with respect to the oscillation. Moreover, all recorded neurons that met the electrophysiological criteria for fast spiking cells oscillated in phase with the EEG. A nonpyramidal aspiny neuron (Fig. $1 C$ ) had the same relation of phase with the focal EEG.

The relation with the surface and depth EEG is shown in Figure 2 for a dual, simultaneous intracellular recording from left area 4 and the homotopic focus in the contralateral area 4. Both neurons were oscillating at a frequency of around $0.7 \mathrm{~Hz}$. They showed roughly synchronous hyperpolarizations during the depth-positive component of the EEG, recorded close to the micropipettes (left). The hyperpolarization lasted a minimum of $0.17 \mathrm{sec}$ and a maximum of $0.5-0.7 \mathrm{sec}$. It was interrupted in both cells, in a roughly synchronized manner, by a phasic excitation coincident with a depth-negative wave. The initial excitation was followed by a depolarizing plateau in which there was tonic firing at a frequency proportional to the level of depolarization. On the right side of Figure 2, a superimposition was made of fragments of the spontaneous activity, centered on successive negative peaks of the depth EEG in the left area 4. The cell and the EEG from the right area 4 were then aligned to the same reference. It demonstrated the consistency and the synchronization of the depth positivity in the two hemispheres that corresponded to the hyperpolarization of both cells. It also shows a certain temporal distribution of the beginning of the cellular excitation relative to the EEG. This is expected, as the EEG waves are considered to be the average of currents from many cells. Due to the superposition procedure, the details of the EEG oscillatory behavior during the depolarizing phase were lost, but spindle oscillations can be clearly observed as paced by the slow rhythm (see arrowhead, left area 4 on the right side of Fig. 2).

As shown above, the depolarizing phase of the oscillation in cortical cells could be crowned by depolarizing wavelets at the frequency range $(7-15 \mathrm{~Hz})$ of spindle oscillations (see Fig. $1 A, B)$.

\footnotetext{
Figure 1. Pyramidal and nonpyramidal cortical cells oscillate in phase. Left panels show intracellular recordings and simultaneously recorded EEG in the vicinity $(\approx 1 \mathrm{~mm})$ of the cell. The EEG was recorded by means of coaxial electrodes located on the surface and at a depth of $\approx 0.6 \mathrm{~mm}$. In this and following figures, polarity of EEG and evoked field potentials is as for intracellular recordings (positivity up). Right panels are the corresponding cells stained with Neurobiotin (calibration bars in millimeters). A, Pyramidal cell from the somatosensory cortex (area $3 \mathrm{~b}$ ) at $1 \mathrm{~mm}$ depth. Note the presence of two apical dendrites and the track left by the recording micropipette on the left side of the cell. The cell oscillated at $0.9 \mathrm{~Hz}$ with depolarizing phases corresponding to depth-EEG negative (surface-positive) potentials. $B$, Superficial pyramidal cell ( $0.3 \mathrm{~mm}$ from the surface, seen in the upper part of the photo). This cell was extremely spiny and showed a prominent local arborization of its axon. It oscillated with a frequency of $0.6 \mathrm{~Hz}$ and often showed clear EPSPs at the frequency of spindle oscillations (see the first depolarizing period), grouped by the slow oscillation. Note correspondence between the missing cycle (after the third depolarization) in the cellular oscillation as well as the EEG. $C$, A nonpyramidal cell was recorded at $1.1 \mathrm{~mm}$ depth. Note the absence of spines. This cell oscillated at $0.9 \mathrm{~Hz}$. In this and following figures, $V_{m}$ is indicated.
} 


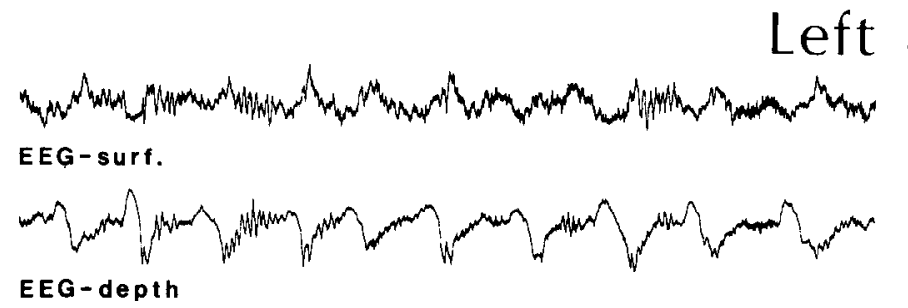

area 4



Intra-cell

Right area 4
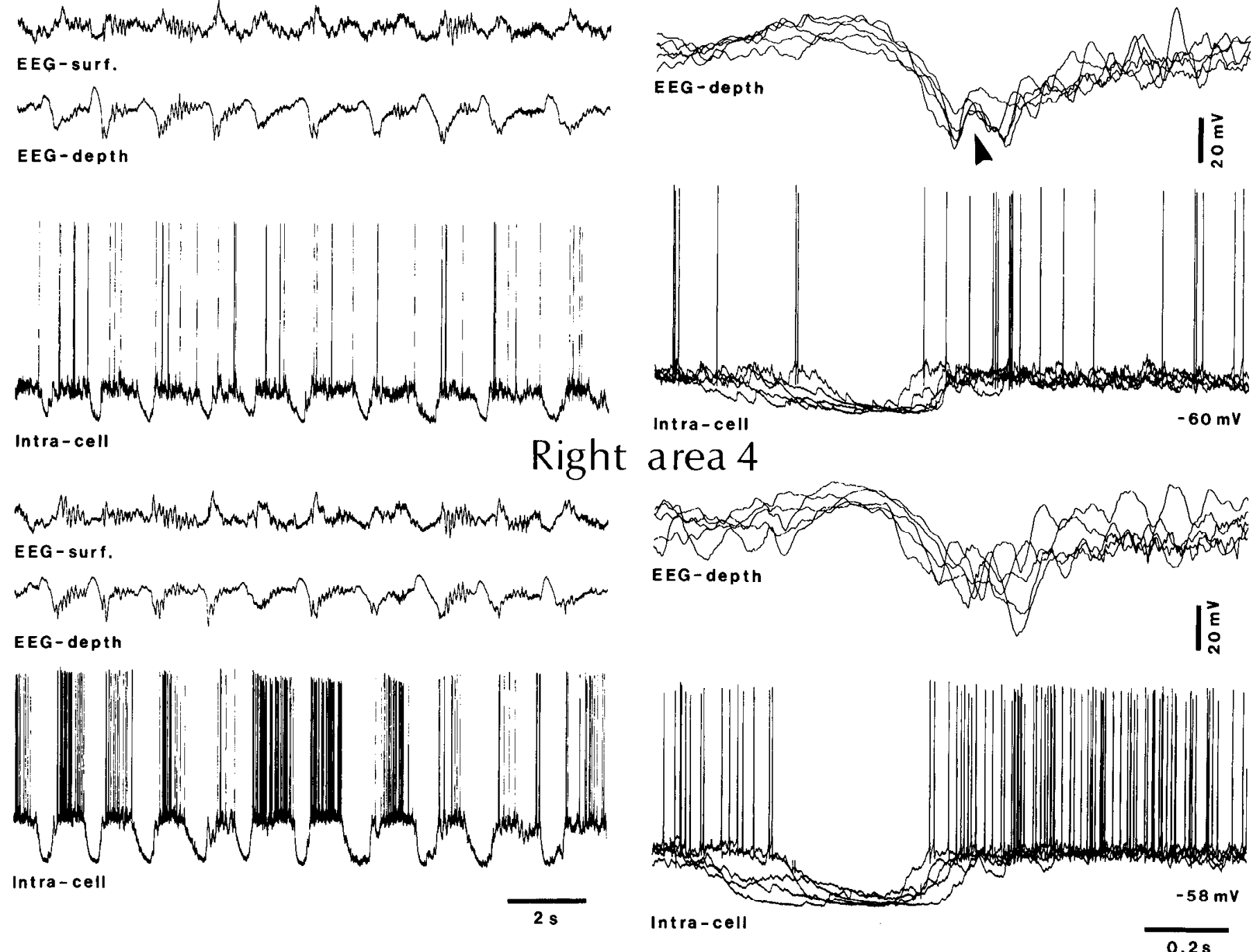

Figure 2. Intracellularly recorded cortical cells oscillate in phase. A neuron from the left motor cortex (Left area 4 ) was recorded simultaneously with a cell from the homotopic motor cortex (Right area 4), as well as with surface and depth EEG from left and right areas 4 . Left panel shows raw data. Both cells were oscillating at $\sim 0.7 \mathrm{~Hz}$. Note the presence of spindle sequences grouped by the slow oscillation. Right panel was constructed using the successive negative peaks of the depth EEG from the left hemisphere as zero-time reference for the alignment of all other traces. Note the rough simultaneity of cellular hyperpolarization and depth-EEG positivities. Arrowhead in right panel with superimpositions marks the onset of oscillation within the frequency range of spindles.

Figure $3 A$ shows an example of a spontaneous spindle sequence in a motor cortical cell. The spindle sequence was preceded by a hyperpolarization that lasted for $0.14 \mathrm{sec}$ and corresponded to a positivity in the depth EEG. The hyperpolarization was followed by EPSPs and spike trains at a frequency of $14 \mathrm{~Hz}$ that corresponded to EEG depth negativities and presumably originated in TC cells. A nearly identical sequence of events was triggered by applying a stimulus to the VL nucleus. The initial response, characteristic of the stimulation of specific thalamocortical projections, consisted of an EPSP leading to discharges and corresponded to a biphasic negativity in the depth EEG. The initial response was followed by a long-lasting hyperpolarization and a depolarizing spindle sequence which showed the same relation with the EEG as the one occurring spontaneously.

The response to intracortical stimulation (not shown) was characterized by an initial EPSP that had a longer duration than after thalamic stimulation (Creutzfeldt et al., 1966a), followed by the same sequence of events as those described for VL stimulation.

The hyperpolarizing phases of the slow oscillation varied in duration from one cycle to another or between different responses to electrical stimulation. More importantly, the fluctuations of a cell's hyperpolarization occurred in parallel with those of the depth-EEG positivity. This is illustrated in the example of Figure $3 B$. A motor cortical cell responded to $\mathrm{VL}$ thalamic stimuli of constant intensity and duration with an initial EPSP, that had the same duration and amplitude, followed by a hyperpolarization that varied in duration between $60 \mathrm{msec}$ to $230 \mathrm{msec}$, in close time relation with the depth-EEG positivity. As a consequence, the onset of the cellular afterdischarge jittered together with the depth-EEG peak negativity. This indicates that the cortical cell population, represented by the EEG, initiates an afterdischarge that follows a variable period of synchronized hyperpolarization. 
A

Spontaneous
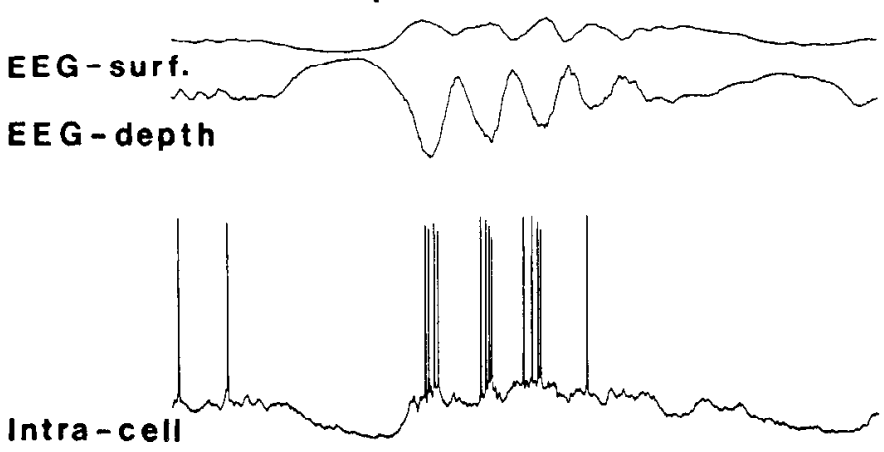

area $4-62 \mathrm{mV}$
Evoked
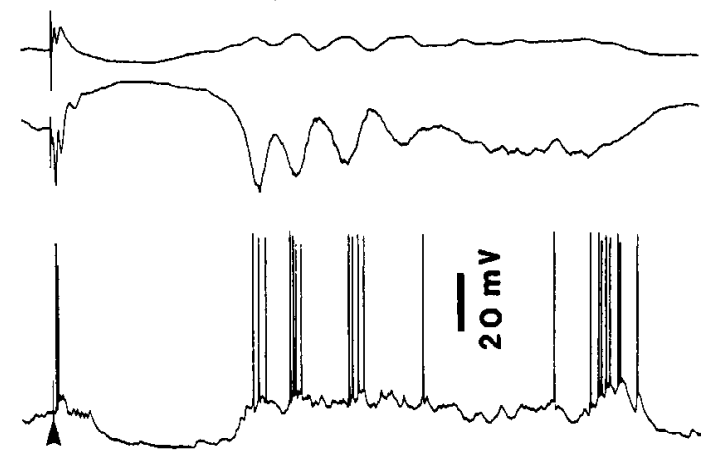

$0.1 \mathrm{~s}$

B
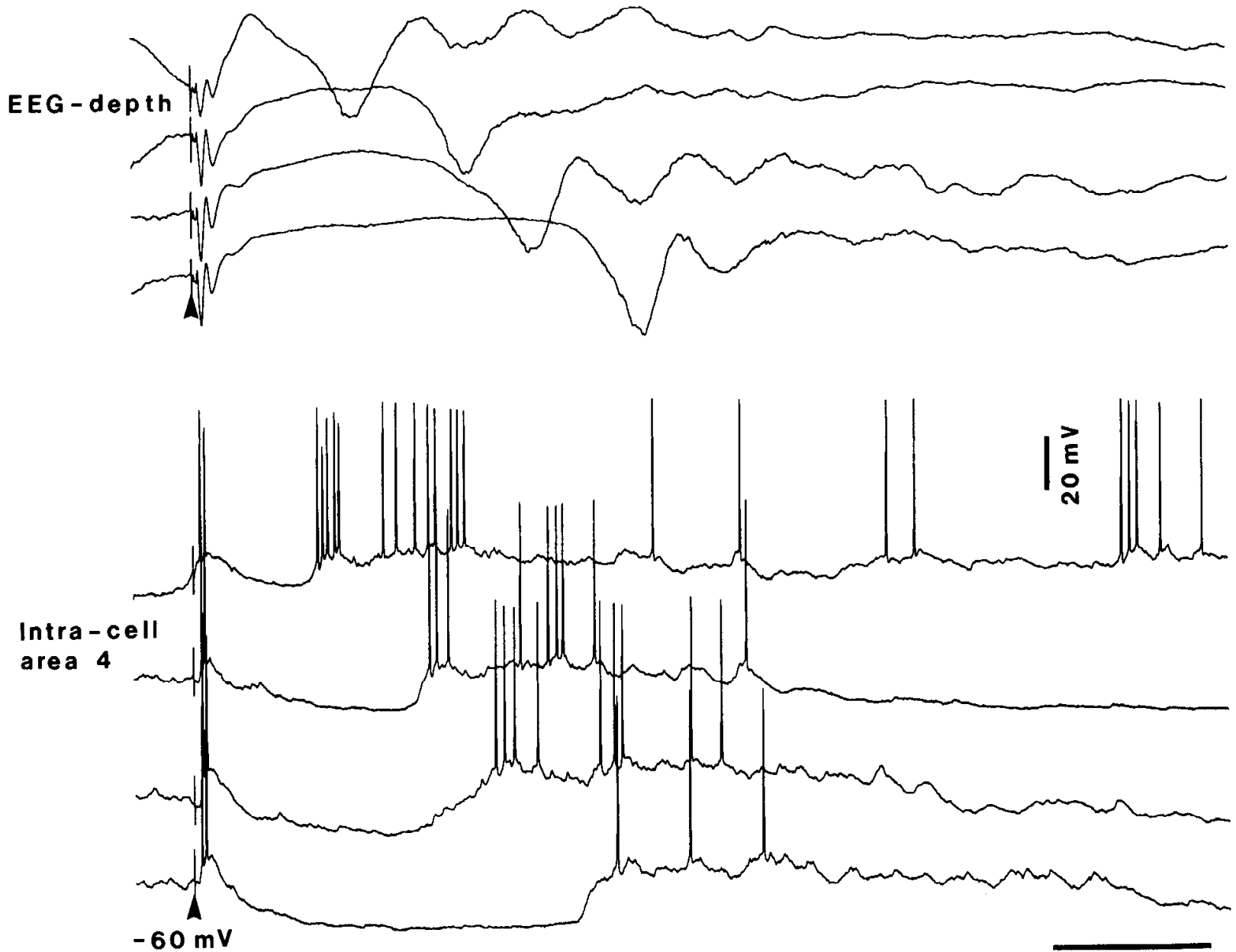

$0.1 \mathrm{~s}$

Figure 3. The duration of hyperpolarizations varies in parallel with that of depth-EEG positive waves. $A$, A slowly oscillating motor cortical cell (Spontaneous). The depolarizing spindle wavelets at $14 \mathrm{~Hz}$ followed a period of $140 \mathrm{msec}$ hyperpolarization and corresponded one-to-one with depth-EEG negative potentials. VL thalamic stimulation (Evoked, arrowhead) evoked an EPSP leading to cell firing that was followed by a hyperpolarization of $180 \mathrm{msec}$. The hyperpolarization gave rise to a spindle sequence at $14 \mathrm{~Hz}$ that was in phase with depth-EEG negative waves at the same frequency. $B$, Four different responses to VL thalamic stimulation (arrowhead) of the same cell (from area 4) are shown together with the simultaneously recorded depth EEG. The duration of the evoked hyperpolarization varied randomly from a minimum of 60 msec (upper trace) to a maximum of $230 \mathrm{msec}$ (bottom trace), in parallel with the depth-EEG positive potential. Note that the initial evoked response, consisting of an EPSP giving rise to two spikes (associated with a depth-EEG biphasic negative potential), was constant through different trials. 

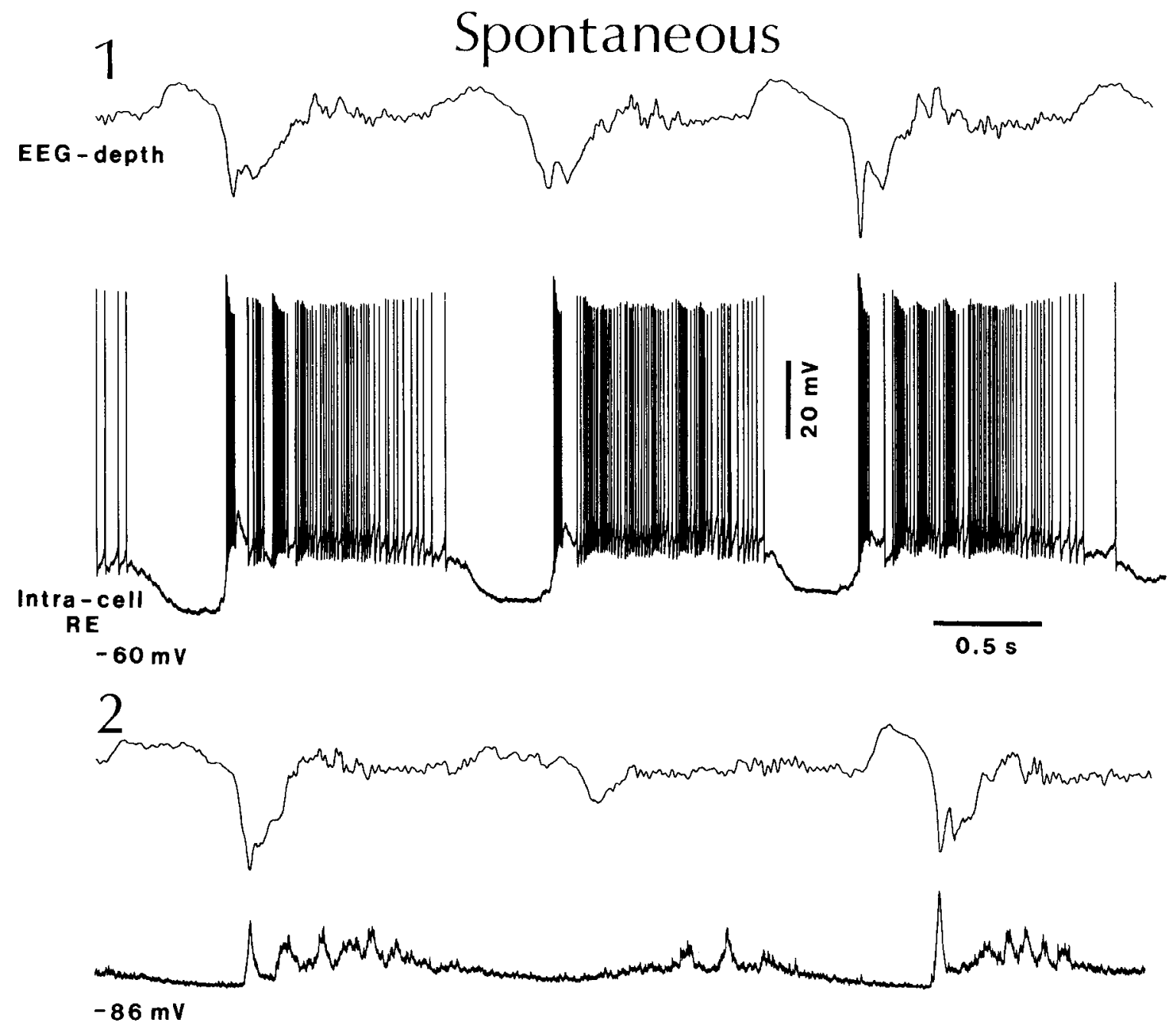

Evoked

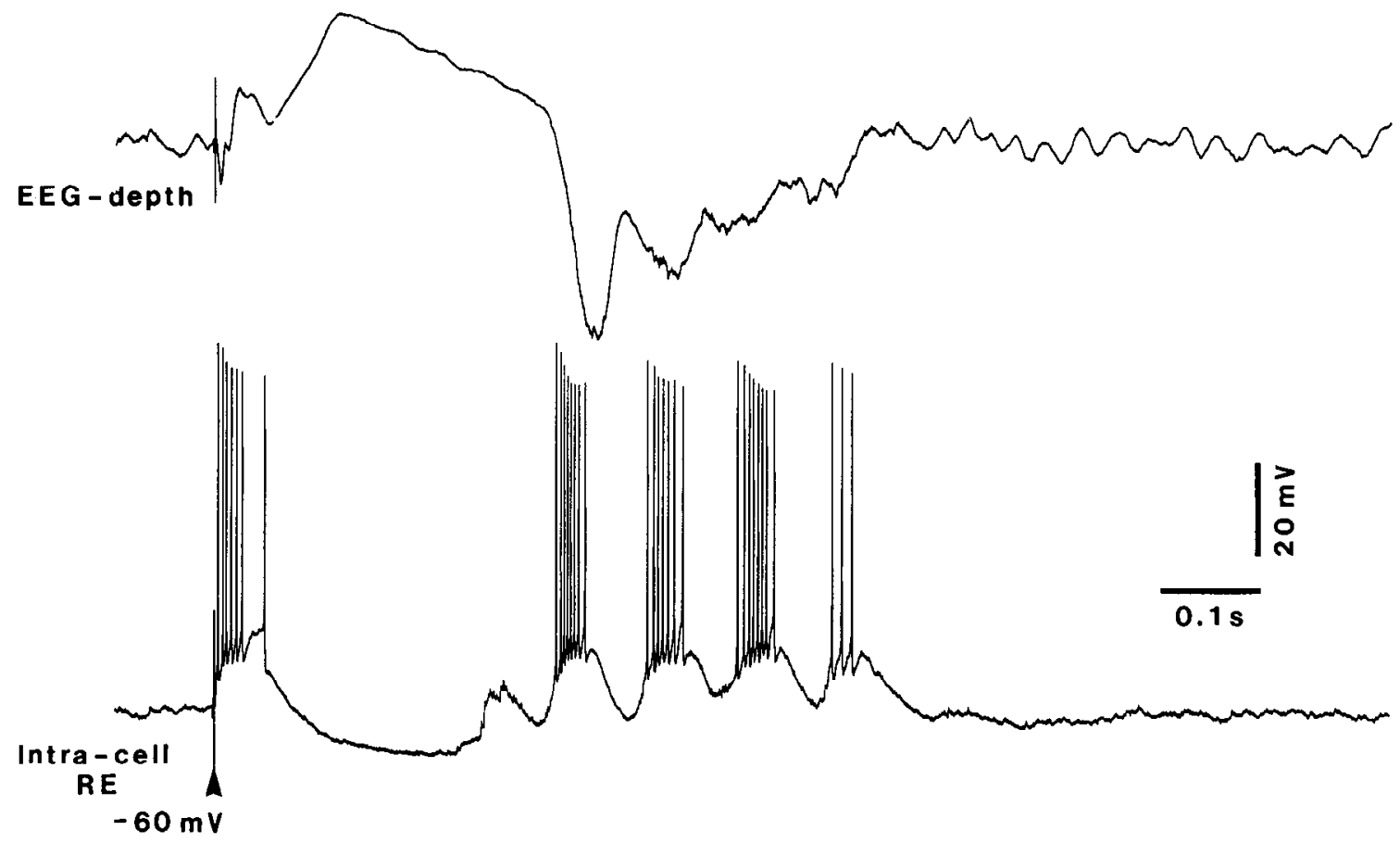




\section{Reticular thalamic cells}

During the EEG complexes described above, characterizing the spontaneous slow oscillation, RE cells displayed a hyperpolarization coincident with the depth-EEG positivity that was ended by a phasic excitation roughly in synchrony with the depth-EEG negative deflection (Fig. 4). The initial excitation was usually followed by a sequence of spike bursts over a depolarizing envelope, characteristic of spindle oscillations in RE cells recorded in vivo (Mulle et al., 1986; Contreras et al., 1993). The depolarizing period that followed the initial phasic excitation could, as well, be associated with a tonic discharge modulated at the spindle frequency. In this case, DC membrane hyperpolarization revealed underlying EPSPs at the frequency of spindles (Fig. 4, Spontaneous). In other instances, however, RE cells fired tonically following the initial burst, with a frequency proportional to the level of depolarization, reaching values up to 50 or $60 \mathrm{~Hz}$.

Upon stimulation of the internal capsule (Fig. 4, Evoked), the cortex, or the DCN (in the case of peri-VP cells), RE cells responded with a high-frequency spike burst followed by a period of hyperpolarization of variable duration and amplitude (Mulle et al., 1986; Contreras et al., 1993) that generally gave rise to a spindle sequence. The evoked spikc burst was coincident with a depth-EEG biphasic negativity and was followed by the same sequence of events as those characterizing the spontaneous activity. In Figure 4 the RE cell showed a hyperpolarization lasting for $0.2 \mathrm{sec}$ followed by a spindle sequence whose first wavelet was smaller in amplitude and had no correlate in the cortical EEG. This showed that groups of cells may escape hyperpolarization up to $0.1 \mathrm{msec}$ before the bulk of the population participating at each oscillatory episode.

The consistency of the relations between RE cells and the EEG is further illustrated in Figure 5, where successive peak negativities of the depth EEG, during a period of spontaneous oscillation, were used as a zero-time reference for the alignment of cellular events. At a relatively depolarized level $(-55 \mathrm{mV})$, spontaneous hyperpolarizations, coincident with the depth-EEG positivities, lasted for $\sim 0.3 \mathrm{sec}$ and had amplitudes of 12-15 $\mathrm{mV}$, de-inactivating a low-threshold spike (LTS) and leading to rebound burst discharges during the depth-EEG first negative deflection. Spindle wavelets in the EEG and modulation of the $\mathrm{RE}$ cell's tonic tail at the spindling frequency were blurred by the superimposition procedure. Hyperpolarizing the cell with DC injection diminished the amplitude of the hyperpolarizing phase of the oscillation, which was almost abolished at -90 $\mathrm{mV}$ (Fig. 5). At this $V_{m}$, clear signs of increased input conductance were seen: the last $0.2 \mathrm{sec}$ of the hyperpolarizing phase showed no signs of synaptic activity, the beginning of the depolarizing phase was delayed and more abrupt as compared to $-55 \mathrm{mV}$, and the burst response was clearly diminished in size compared to the spike burst at $-55 \mathrm{mV}$ (three spikes against nine; see details indicated by arrows, Fig. 5). For increased input conductance with hyperpolarization of RE cells, see also Figure 2 in Contreras et al. (1993).

As previously shown for cortical cells (see Fig. 3), the duration of the hyperpolarizing phase, resulting from stimulation or occurring spontaneously, varied randomly from 50 to several hundreds of milliseconds in close relation with the variations in the depth-EEG positive wave. In the example of Figure 6, four different responses to intcrnal capsulc shocks of constant intensity are shown from a cell located in the rostrolateral sector of the RE nucleus. The corticothalamic volleys elicited a highfrequency spike burst with fairly constant characteristics, followed by a hyperpolarization that varied in duration from 60 to $220 \mathrm{msec}$ and led to a spindle sequence. The variations in duration of the hyperpolarization and, therefore, the time of initiation of the spindle sequence closely corresponded to the time course of the depth-EEG positivity. This indicates that populations of cortical cells (represented by the EEG) and RE cells undergo hyperpolarizations of similar durations and are, therefore, synchronized at the onset of the afterdischarge.

In a few cases $(n=3)$ in which the electrodes were well positioned (as indicated by a very low threshold of RE activation from the cortical electrode), we detected a clear relation between the amplitudes of EEG and cellular events; namely, spindles were more robust and better defined in RE cells for depth-EEG negativities of higher amplitude (see an example in Fig. 4, Spontaneous 2).

\section{Thalamocortical cells}

The location of the TC cells studied here was confirmed by staining some of them $(n=5)$ with Neurobiotin. The cell shown in Figure 7 was a typical bushy cell (see Jones, 1985). It responded with an EPSP to stimulation of the internal capsule ( $V_{m}=-60 \mathrm{mV}$ ) that gave rise to an isolated LTS when the cell was hyperpolarized $\left(V_{m}=-70 \mathrm{mV}\right)$. With further hyperpolarization $\left(V_{m}=-75 \mathrm{mV}\right)$ the LTS was further de-inactivated and occasionally reached the threshold for generation of fast action potentials. The response of this cell to depolarizing current pulses of constant amplitude consisted of tonic firing $(-65 \mathrm{mV})$, or burst firing when the cell was hyperpolarized with DC current $\left(V_{m}=-80 \mathrm{mV}\right)$. At intermediary $V_{\mathrm{ms}}(-70 \mathrm{mV})$ the cell showed a passive response. The same neuron responded with a rebound burst at the break of a hyperpolarizing pulse (Deschênes et al., 1984; Jahnsen and Llinás, 1984).

The general behavior of TC cells during the slow oscillation is shown in Figure 8. The intracellularly recorded VL neuron oscillated at $0.8 \mathrm{~Hz}$ and gave rise to rebound bursts at almost every cycle of the oscillation (Fig. 8A). The cell was recorded simultaneously with the depth EEG from the motor cortex and the focal waves picked up by a bipolar thalamic coaxial electrode located $1 \mathrm{~mm}$ posteriorly to the neuron. The negative peaks of the depth-EEG activity were taken as a zero-time reference, and both the VL cellular activity and the thalamic focal waves were aligned to it (Fig. $8 B$ ). A clear hyperpolarization of about 15 Figure 4. Reticular thalamic neurons oscillate in phase with the cortical slow oscillation. An RE neuron was recorded from the rostrolateral sector,
simultaneously with the depth EEG from the motor cortex. Both the cell and EEG oscillated spontaneously at $0.6 \mathrm{~Hz}(S p o n t a n e o u s)$. At $-60 \mathrm{mV}$
(in 1) the depolarizing phases were characterized by an initial burst discharge followed by tonic firing modulated at the spindle frequency. When
the cell was hyperpolarized ( $-86 \mathrm{mV}$, in 2$)$, EPSPs were revealed at the same frequency as the modulation of the tonic firing. Note in 2 the
correlation between the amplitude of EEG waves and that of cellular depolarization. Upon internal capsule stimulation (Evoked, arrowhead) the
cell responded with an initial high-frequency burst followed by a hyperpolarization of 200 msec duration and a spindle sequence riding on a
depolarizing envelope. The first wave of the spindle sequence occurred about $70 \mathrm{msec}$ before the beginning of the depth-EEG negativity (see text). 

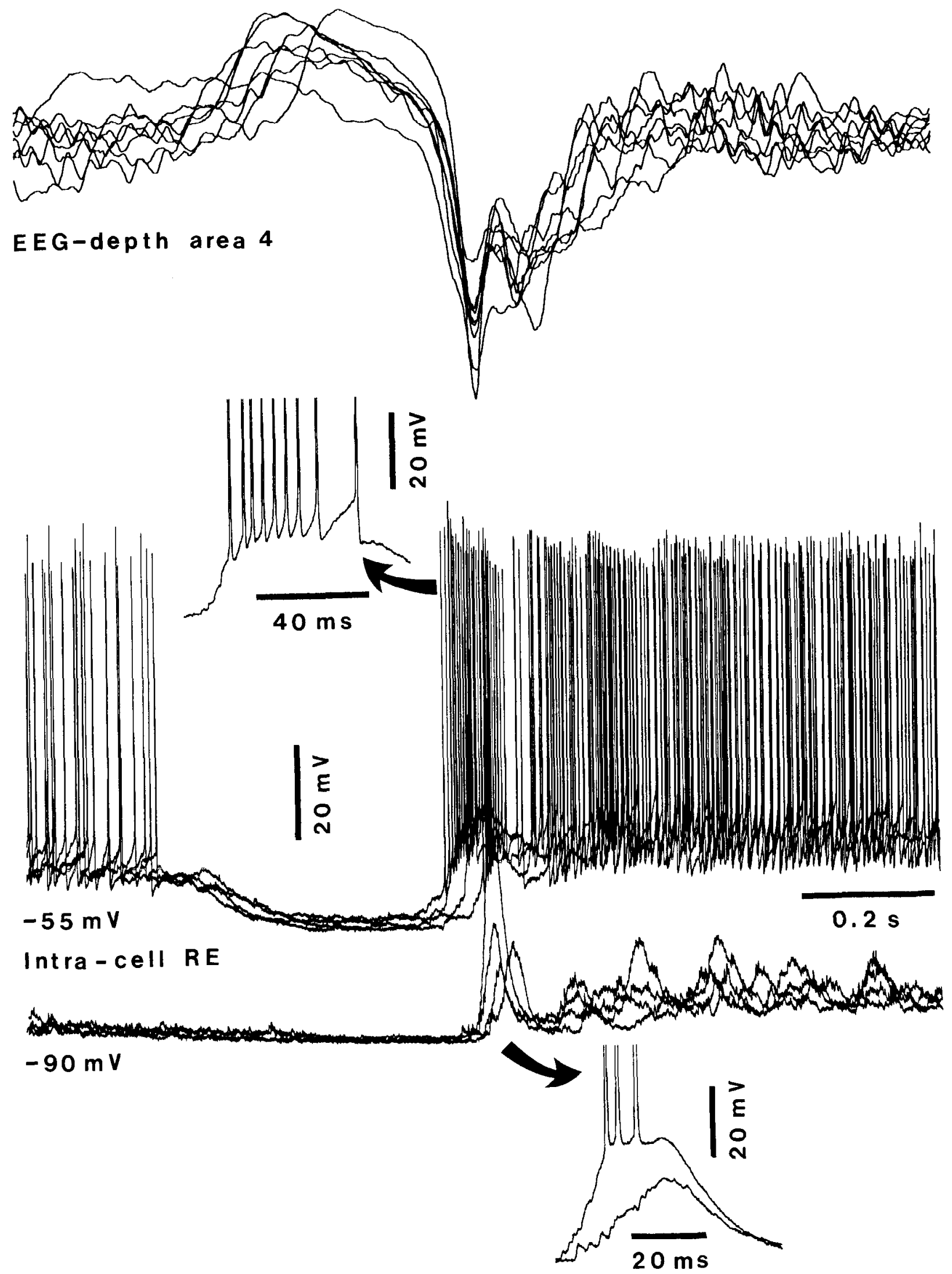

Figure 5. RE cells show a consistent phase relation with the cortical EEG. An RE cell from the rostrolateral sector was recorded simultaneously with the EEG from the motor cortical area 4. Successive peak negativities of the depth EEG from a period of spontaneous slow oscillation were taken as time reference for the alignment of cellular activity. The cell was depolarized $(-55 \mathrm{mV})$ and hyperpolarized $(-90 \mathrm{mV})$ with $\mathrm{DC}$ current. At $-55 \mathrm{mV}$ a $300 \mathrm{msec}$ hyperpolarization, coincident with a depth-EEG positive wave, preceded cellular firing. The sharp negative peak in the depth EEG was reflected in the cell as an excitatory drive that led to a burst discharge (see detail indicated by arrow). At $-90 \mathrm{mV}$ the hyperpolarizing phase was almost abolished and the phasic excitation from the cortex led to burst discharge in only one case. The postinhibitory rebound diminished in size and duration (see detail indicated by arrow). 

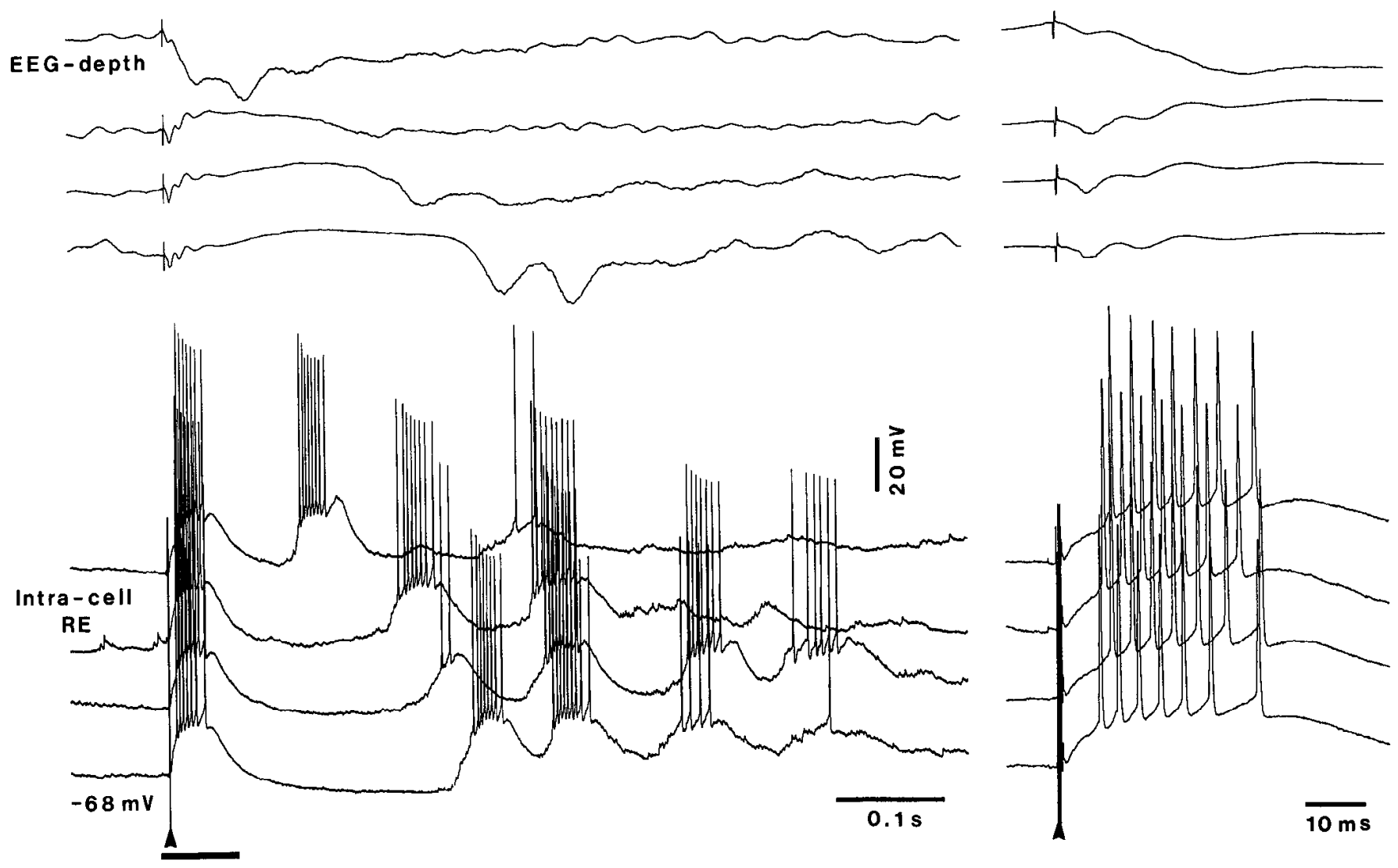

Figure 6. The duration of the evoked hyperpolarization in RE cells varies in parallel with the duration of depth-EEG positive potentials. A cell from the rostrolateral sector of the RE nucleus responded to stimulation of the internal capsule (arrowhead) with a high-frequency burst followed by a long-lasting hyperpolarization that gave rise to a depolarizing spindle sequence. The depth EEG from the motor cortex was recorded simultaneously. Four different responses, selected for their differences in the duration of the evoked hyperpolarization, are shown with stimuli of constant amplitude. The EEG and intracellular traces correspond one-to-one, from top to bottom. The duration of the hyperpolarizing phase varied randomly and corresponded to that of the EEG-positive waves despite the constancy of the initial burst response and initial cortical field potential (see expanded traces).

$\mathrm{mV}$ in amplitude and $250 \mathrm{msec}$ in duration was coincident with the depth-EEG positive wave. The hyperpolarization ended with a short-lasting depolarizing-hyperpolarizing sequence leading to a rebound burst (detail of the LTS and spike burst shown at left). That the long-lasting hyperpolarization was ended with a synchronous, brief excitation reaching a broad thalamic territory is suggested by the short-lasting negative field potential recorded $1 \mathrm{~mm}$ behind the cell, which was time related with the peak negativity in the depth EEG (Fig. $8 B$, bottom trace).

Other cells (Fig. $8 C$ ) had their burst responses delayed by the hyperpolarization that followed the peak EEG negativities. The cell in Figure $8 C$ showed a discrete hyperpolarization during the depth-EEG positive waves that terminated with a phasic depolarization, in good synchrony with the peak negative wave in the depth EEG. This phasic excitation was followed by a hyperpolarization of abrupt onset that consistently delayed burst firing by about $400 \mathrm{msec}$. This period of cellular hyperpolarization corresponded with depth-EEG wavelets resembling spindle oscillations.

To assess the simultaneity of the phenomena described for cortical and thalamic neurons, dual intracellular recordings ( $n$ $=16$ ) were performed from thalamic VL and motor cortical cells. These recordings confirmed the presence of a hyperpolarization occurring simultaneously in both cell types and coincident with a depth positivity in the EEG recorded from the motor cortex. In the raw data ( $\Gamma i g .9 A 1, B l$ ), cortical and thalamic cells are shown to oscillate spontaneously at $0.8 \mathrm{~Hz}$. In Figure $9 A$, the VI cell was at rest $(-65 \mathrm{mV})$ and the hyperpolarizing phases of the oscillation were of enough amplitude to give rise to rebound spike bursts. In Figure $9 B$, the same cell was depolarized by $D C$ injection so that it fired tonically between the inhibitory periods. The hyperpolarization was of a smaller amplitude and the cell did not fire a rebound burst. An EPSP was, however, visible in rough simultaneity with the peak of the depth-EEG negativity and the onset of the cortical cell excitation. The phase relation between the two cells (cortical and thalamic) was studied by aligning their activity to the peak negativities in the depth EEG (Fig. 9A2,B2). The thalamic burst fring jittered around the peak of the depth-EEG negativity. The duration of the hyperpolarization varied from 0.2 to $0.3 \mathrm{sec}$ in both cells, but, more importantly, a clear-cut period of hyperpolarization synchronously preceded the firing in both cortical and thalamic cell types.

\section{Hyperpolarization as a synchronizing factor}

As already indicated above, a generalized inhibitory and/or disfacilitatory phenomenon seems to be responsible for timing the onset of the depolarizing phase of the oscillation in all three cell types analyzed here.

To strengthen this point, simultaneous intracellular record- 

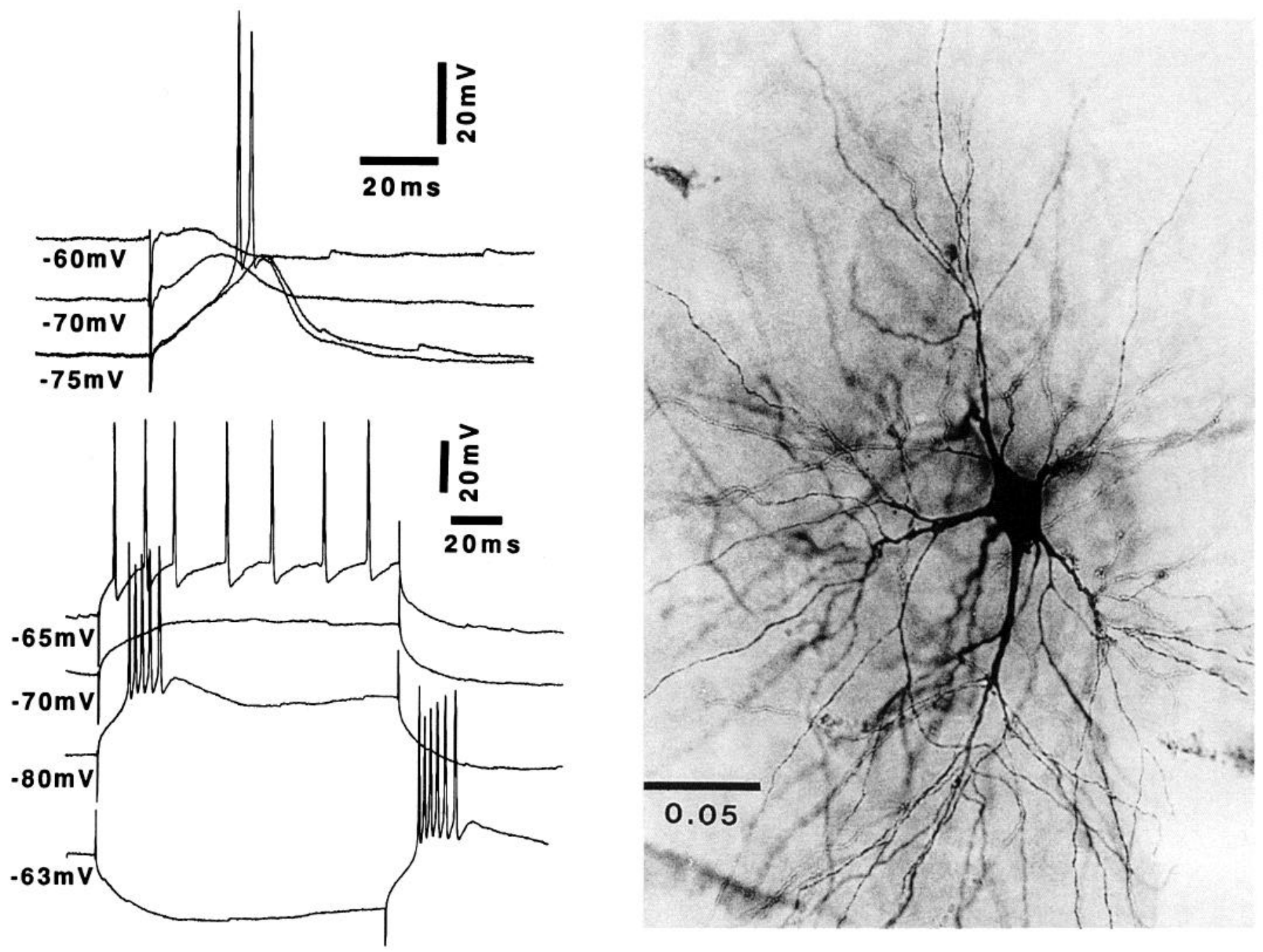

Figure 7. Identification of TC cells. A cell from VL nucleus was stained with Neurobiotin and had a $20 \mu$ m diameter somata with radiating tufted dendrites characteristic of bushy relay neurons. The responses of this cell to internal capsule stimulation are shown on the top left, at three different $V_{\mathrm{ms}}$. Upon DC hyperpolarization the EPSP triggered an LTS that eventually reached the threshold for generation of fast action potentials. Below are the responses of the same cell to depolarizing and hyperpolarizing current pulses at different $V_{\mathrm{ms}}$. Tonic firing (at $-65 \mathrm{mV}$ ) was transformed into burst firing with $\mathrm{DC}$ hyperpolarization $(-80 \mathrm{mV})$. Passive response at $-70 \mathrm{mV}$. Burst firing was also triggered at the break of a hyperpolarizing pulse (bottom trace, $-63 \mathrm{mV}$ ).

ings of pairs of cortical neurons or pairs of cortical and thalamic neurons were observed during transitions from brief EEG desychronizations back into the oscillatory state. In all recorded pairs, cells were brought into the oscillatory state by an initial hyperpolarization. This could happen either simultaneously, the two cells exhibiting a simultaneous hyperpolarization as the first intracellular event leading to oscillation, or with one cell preceding the other, in which case the delayed cell began to oscillate after a few cycles by exhibiting a hyperpolarization that was synchronous with that of the other cell (see also Steriade et al., 1994b). Two examples are illustrated in Figure 10. In Figure $10 \mathrm{~A}$, two cortical cells from the left and right motor cortices were simultaneously recorded during transitions of nonoscillatory behavior to a slow rhythm at $\approx 0.6-0.7 \mathrm{~Hz}$. The transition from a less synchronized to a fully synchronized EEG was marked by hyperpolarizations that occurred in phase in both the left and right cortical neurons. Similar events occurred among cortical and thalamic cells recorded simultaneously (Fig. 10B).

Figure 8. TC cells oscillate in phase with the cortical EEG during the slow oscillation. A, Spontaneous activity from a VL cell recorded simultaneously with the depth EEG from ipsilateral area 4 and focal waves recorded from a thalamic focus located $1 \mathrm{~mm}$ posteriorly to the cell (EThG). A slow oscillatory behavior at $0.9 \mathrm{~Hz}$ was present in all three traces. $B$, The negative peaks from the EEG in $A$ were used as a time reference to align superimpositions from the three traces. The peak negative components in the EEG corresponded to phasic depolarizations in the intracellular recording and to phasic negative field potentials in the EThG, indicative of excitatory activity. The phasic excitation was curtailed by inhibitory inputs. Eventually, a rebound spike burst was triggered. A detail of one burst response is shown at the left. C, A different TC cell is shown that had a much longer delay for spike-burst generation. The cell remained hyperpolarized during the EEG-negative wavelets that followed the center peak. 
A

EEG-depth

area 4 
A

1

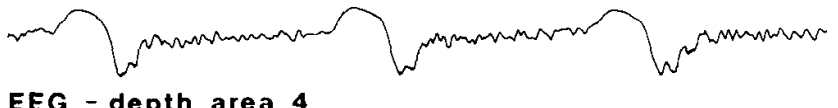

EEG - depth area 4



$-60 \mathrm{mv}$

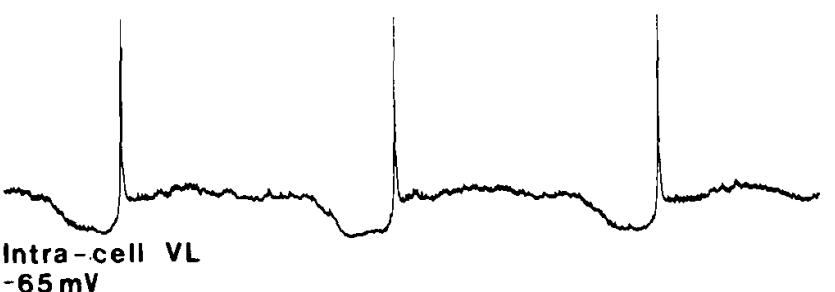

2
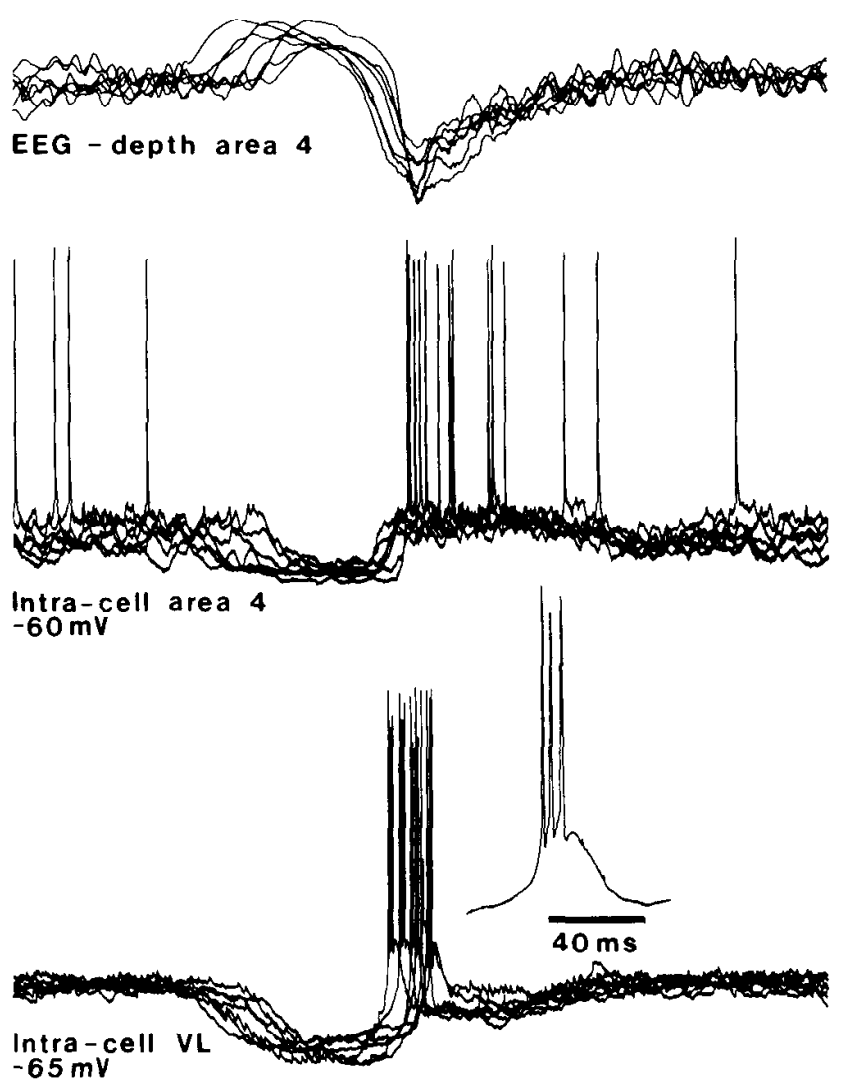
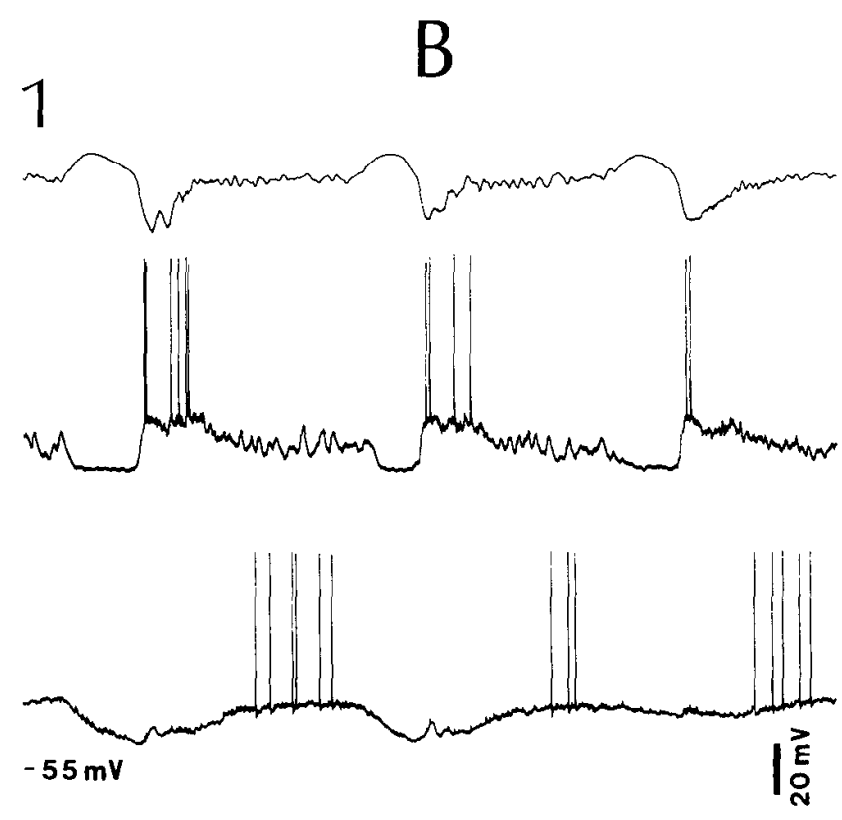

$0.5 \mathrm{~s}$

2
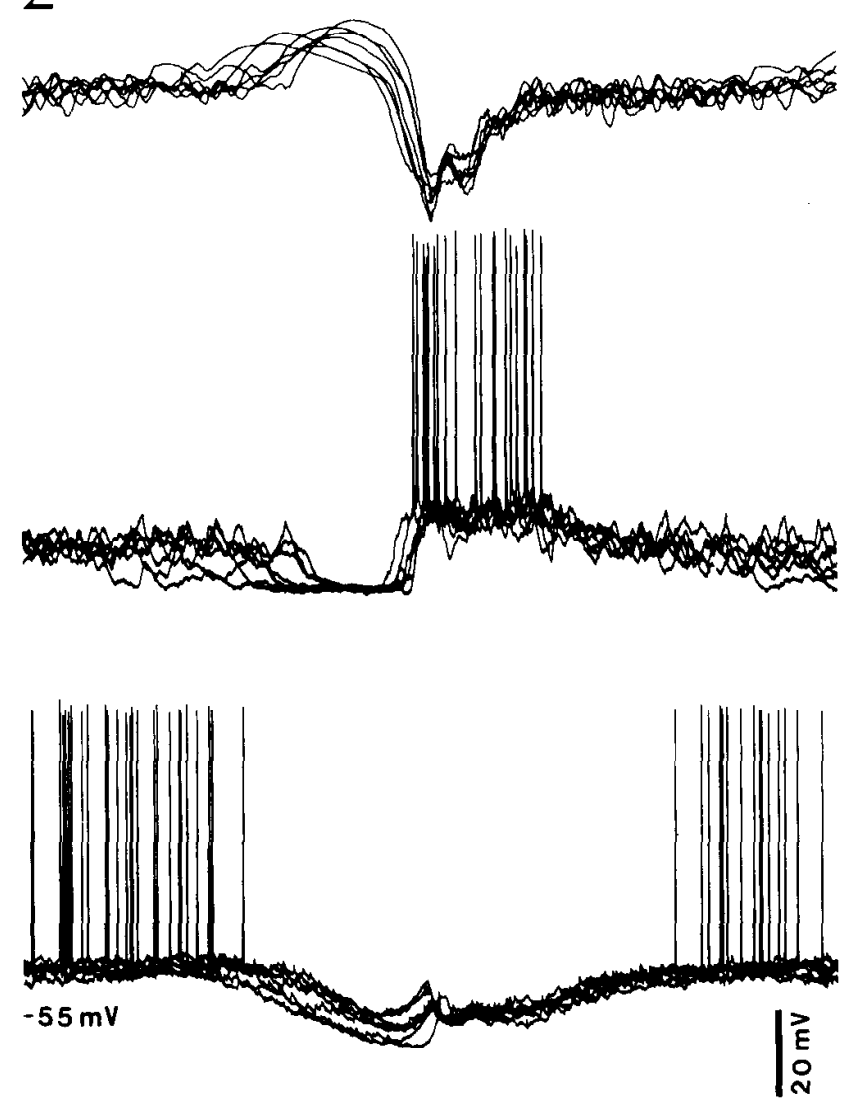

$0.2 \mathrm{~s}$

Figure 9. Simultaneous intracellular recordings from cortical and TC neurons demonstrate their phase relations during the slow oscillation. A cell from the motor cortical area 4 was recorded simultaneously with a TC cell from the VL nucleus. $A 1$, Three cycles of the oscillation at $0.9 \mathrm{~Hz}$, in which the cortical cell fired trains of action potentials during the depolarizing phase of the oscillation and the TC cell fired rebound bursts at the offset of hyperpolarizing phases. $A 2$, Superimposition centered on the EEG peak negativities of seven epochs taken from a period around that shown in $A 1$. An expanded spike burst from the TC cell is illustrated in inset. B1, Data from the same cells, with TC neuron depolarized through injection of $\mathrm{DC}(-55 \mathrm{mV})$. The amplitude of the hyperpolarization corresponding to the EEG positivity was not sufficient to give rise to a rebound burst. $B 2$, Superimposition of seven oscillatory cycles from a period around that shown in $B I$. 

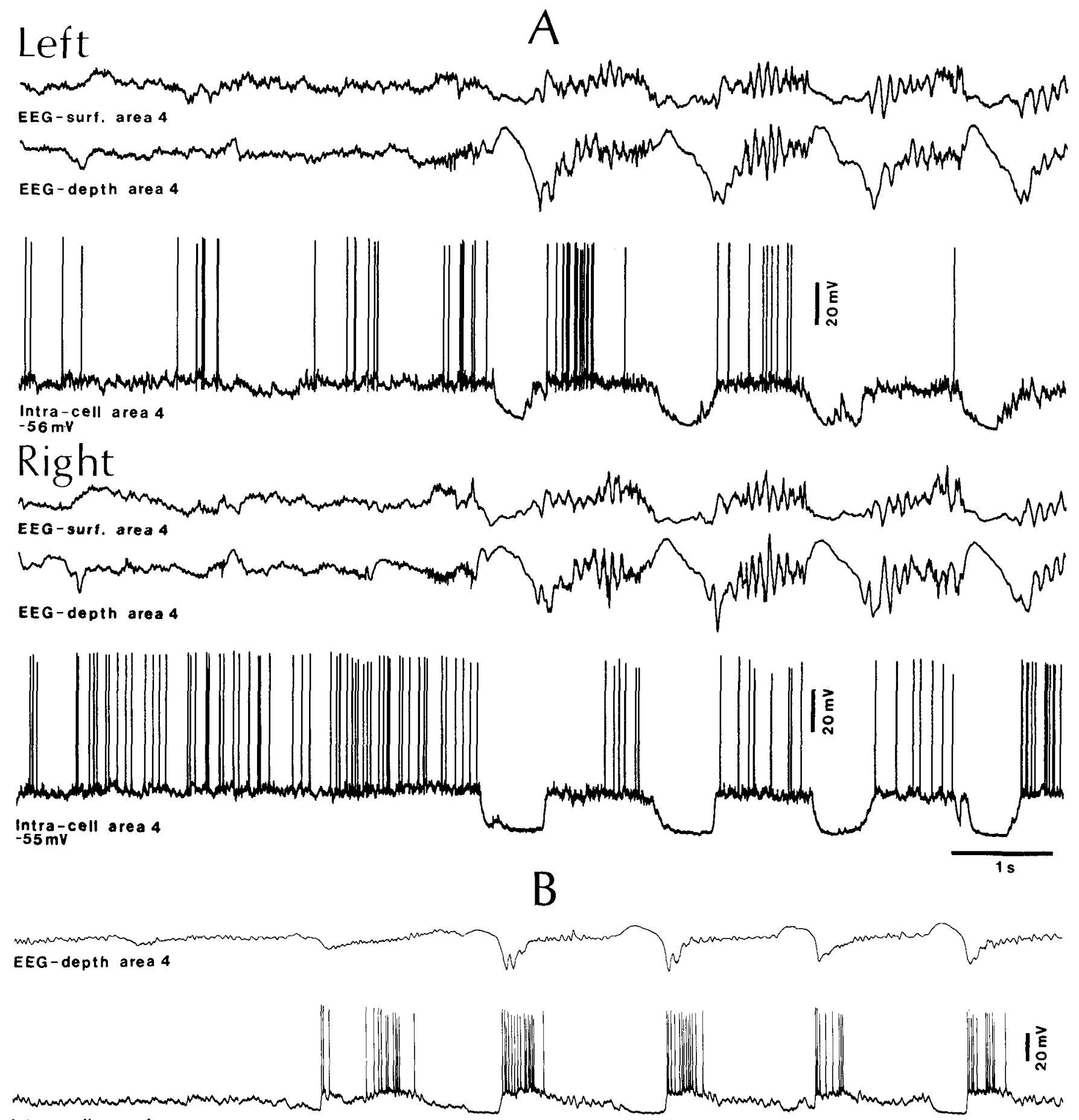

Intra-cell area 4

$-65 \mathrm{mV}$

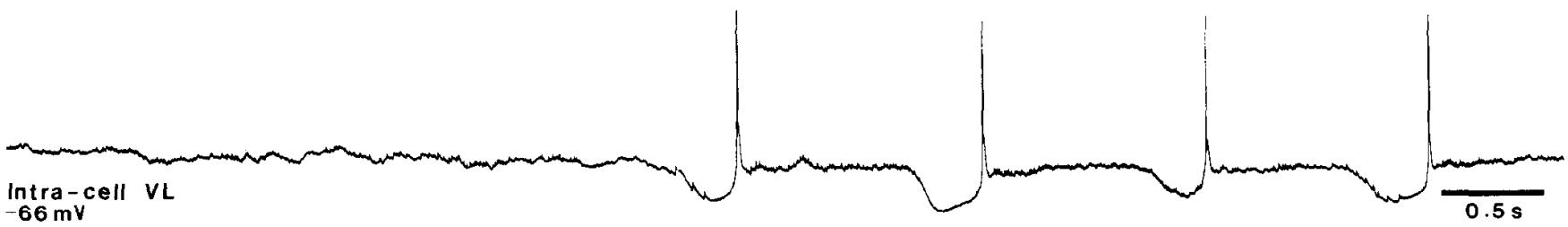

Figure 10. Simultaneous intracellular recordings of cortical and TC cells show that they were entrained into the slow oscillation through an initial hyperpolarization. $A$, Two motor cortical cells from both hemispheres (Left, above; Right, below) were recorded with the corresponding surface and depth EEG. Both cells were entrained into the oscillatory pattern $(\approx 0.6-0.7 \mathrm{~Hz})$ by an initial hyperpolarization that was coincident with a marked increase in the amplitude of the EEG waves, indicative of an increase in synchronization. $B$, A motor cortical cell and a cell from VL, recorded simultaneously, showed a synchronized hyperpolarization coincident with a depth-EEG positivity and the enhancement of the oscillatory activity. 
A $\underset{\substack{E E G-d e p t h \\ \text { area 3b }}}{1} r^{2} N^{3}$

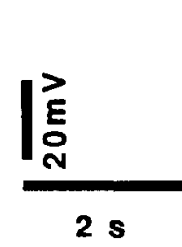
inmovendum

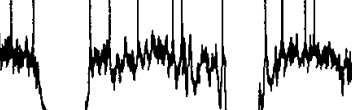
Intra-cell area 3 b
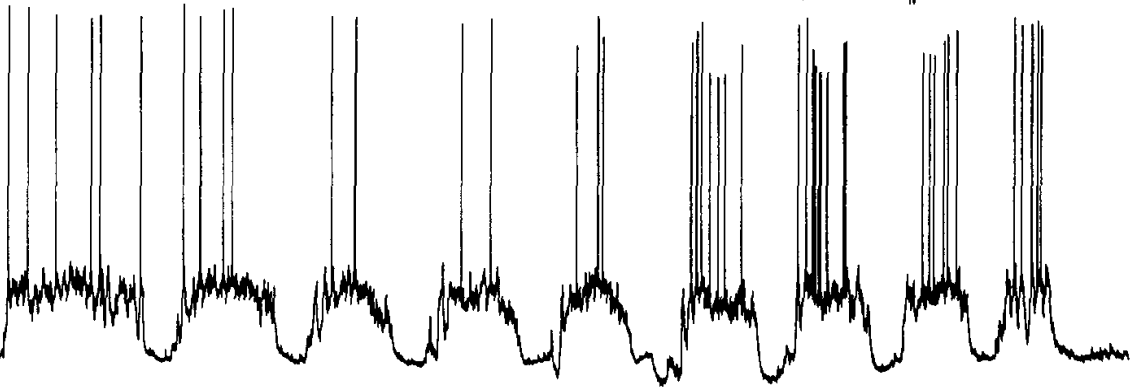

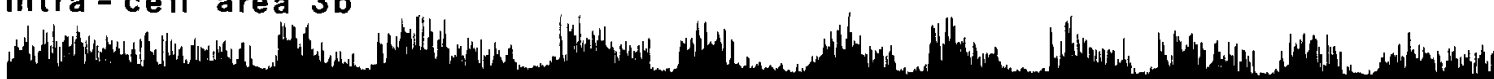



B Extra-cell RE (peri-VP)
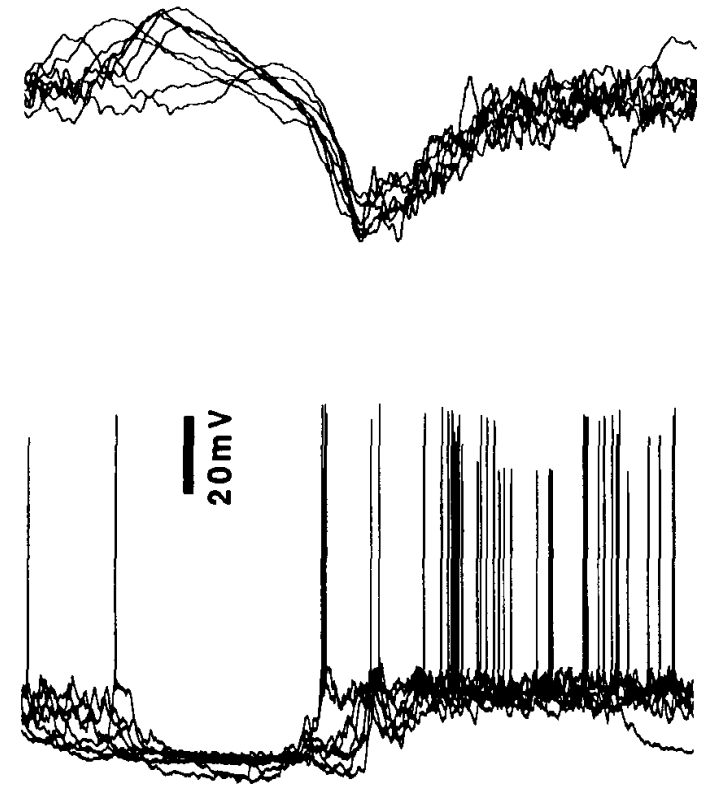

C
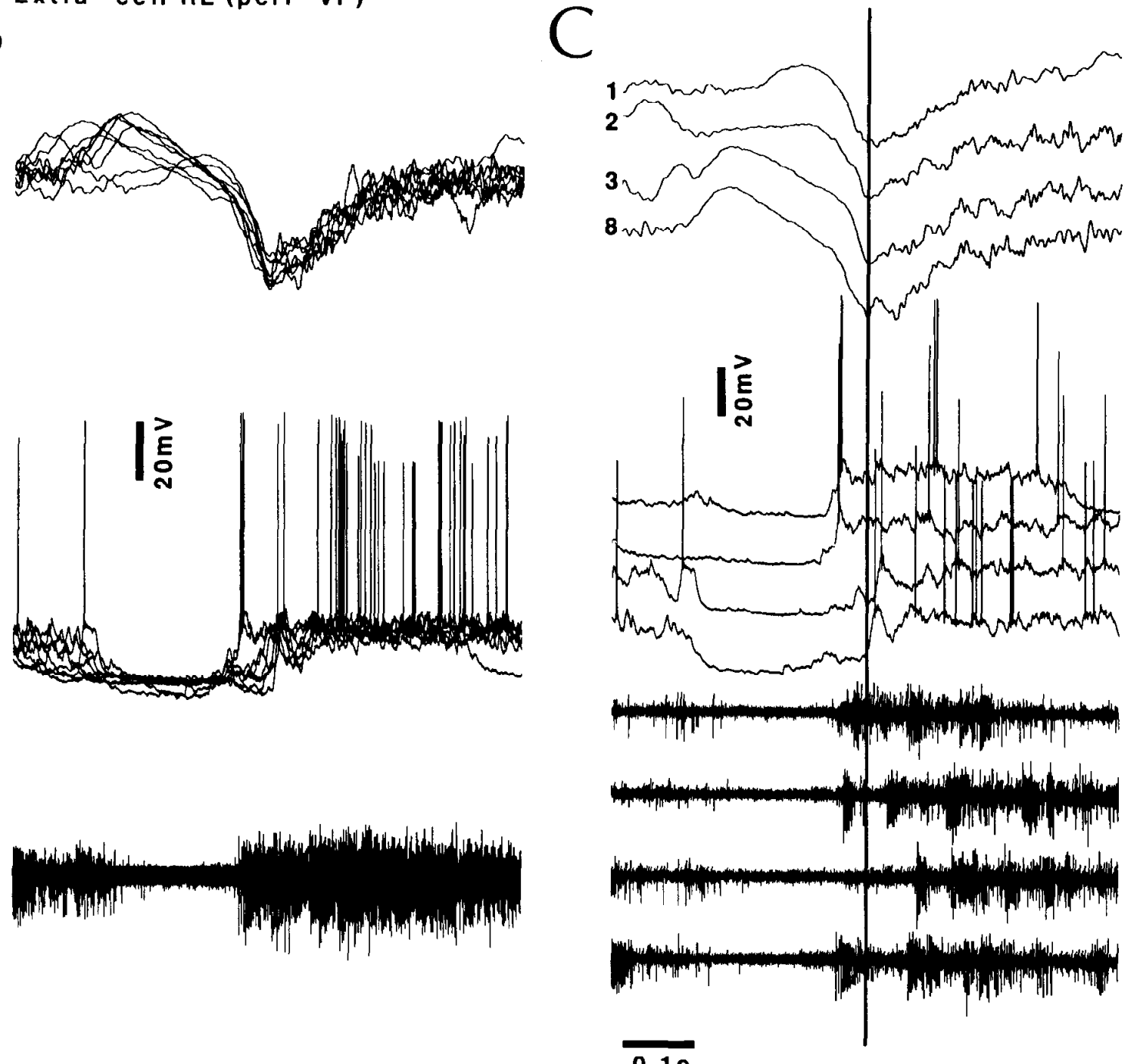
Again, a clear hyperpolarization led both cells into the oscillatory state.

RE cells demonstrated, as well, brief transitions from oscillatory to nonoscillatory states (Fig. 11). The entrainment into oscillation occurred through cellular hyperpolarization that was reflected extracellularly as a silence in firing. In Figure $11 \mathrm{~A}$, an intracellular recording from the primary somatosensory cortex was performed simultaneously with a multiunit extracellular recording in the peri-VP sector of the RE nucleus ( $n=38)$. After short periods of EEG desynchronization, during which the RE cells tended to fire tonically (Steriade et al., 1986), both cells (cortical and RE) began to oscillate together, displaying initially a simultaneous hyperpolarization that was coincident with an initial depth-EEG positivity. The phase relation during the oscillation is shown in the superposition in Figure $11 B$, in which the peak negativities of the depth EEG were taken as zero-time reference and the intra- as well as extracellular traces aligned to it. RE cells showed a clear silence in their firing in good synchrony with a hyperpolarization in the cortical cell and a depthEEG positive wave. Although the cellular firing of both cells jittered considerably around the time zero (Fig. $11 \mathrm{C}$ ), with delays of $70 \mathrm{msec}$ for the cortical cell and up to $100 \mathrm{msec}$ for the RE cell (compare 1 and 2 with 3 and 8), EPSPs in the intracellularly recorded cortical ncuron were faithfully in phase with the depth-negative wave.

\section{Discussion}

Our results show a close temporal relation between various components of sleep EEG and well defined hyperpolarizing and depolarizing components of cortical and thalamic activities. The relations proved to be similar for spontaneous oscillations within the frequencies of slow and spindle rhythmicities as well as for responses evoked by corticothalamic or thalamocortical volleys. We think that the present data are part of a comprehensive repertoire shedding light on the cellular substrates of major aspects of EEG activity, ranging from long-lasting waves to phasic events, characteristic of resting sleep in animals and humans. Note that similar aspects of the slow oscillation recorded under anesthesia were observed intracellularly in the undrugged isolatcd forcbrain (cerveau isolé preparation) and, at the EEG level, during natural sleep of cats and humans (Steriade et al., 1993c,d).

\section{A general inhibitory mechanism underlies synchronization of low-frequency neuronal oscillations in corticothalamic networks}

The current hypotheses toward the understanding of cortical EEG generation are based on a dipolar arrangement of the currents originated from synaptic inputs and intrinsic properties of pyramidal neurons (Pedley and Traub, 1990; Lopes da Silva, 1991). Thus, a surface-negative EEG potential may be interpreted either as an excitation of apical dendrites resulting from corticocortical inputs to superficial layers and afferents from medial thalamic nuclei depolarizing distal dendrites in layer 1 (Glenn et al., 1982), or as an inhibition in deep layers. As well, surface-positive EEG waves are thought to reflect excitations in middle and deep layers due to inputs from specific thalamic nuclei or inhibitory events in superficial layers. These simple schemes become extremely complex when simultaneous excitatory and inhibitory inputs to different cortical depths are considered.

The present data demonstrate that a long period of hyperpolarization, up to $0.8 \mathrm{sec}$, occurs in cortical, RE, and TC cells in association with a depth-positive (surface-negative) EEG wave. This hyperpolarization is followed by a period of excitation, initiated within a narrow time window in these three cell types and reflected at the EEG level by a depth-negative (surfacepositive) sharp potential. We emphasize that virtually all pyramidal-shaped cortical cells recorded from layers 2-6 as well as aspiny stellate cells displayed the same phase relation with the gross EEG components of the slow rhythm (see Fig. 1). This result corroborates recent data reporting that an overwhelming proportion $(88 \%)$ of cortical neurons oscillated at the slow rhythm and that repetitive IPSPs were seen upon the depolarizing component in pyramidal cells, thus suggesting the participation of local-circuit inhibitory cells in the oscillatory process (Steriade et al., 1993c). Because of this extensive distribution, involving major cell classes throughout cortical layers, we propose that the potentials underlying the slow oscillation are generated through a simultaneous activation of afferent systems in such a way that a single, large sink from layers $2-6$ is produced, whose source is most probably represented by the meshwork of apical dendrites ramifying in layer 1 . This view is supported by a steeper and higher-amplitude signal obtained from the depthEEG electrode. Experiments in progress, designed to analyze the sink-source arrangements, revealed that the excitatory component of the slow oscillation is reversed in the upper part of layer 2 , whereas the inhibitory component reverses more deeply in the cortex.

As EEG oscillations represent synchronized rhythmic behavior in large neuronal pools, a general mechanism would be required to bring together cortical and thalamic neurons. Although single cortical cells continue to oscillate at the slow rhythm after thalamectomy (Steriade et al., 1993c), the synchronization among different cortical neurons was not assessed in those experiments. Moreover, thalamic stimulation was effective in modulating the frequency of the slow cortical oscillation (Steriade et al., 1993c). This suggests that full synchronization of corticothalamic networks may involve feedback cortical projections from thalamic neurons that reflect the slow oscillation (Steriade et al., 1993e). In the present experiments we recorded from two major cell classes in the thalamus, RE and TC neurons, whose activities are playing an important role in the synchronization process as the former have access to widespread territories of the dorsal

\section{$\leftarrow$}

Figure 11. Cortical and RE thalamic cells oscillate in phase during the slow oscillation. $A$, An intracellular recording from a somatosensory cortical cell was performed simultaneously with the depth EEG from the same region and a population of RE cells from the peri-VP sector. A short period of EEG desynchronization (left) was reflected as tonic firing in the RE population. The transformation into an EEG oscillatory pattern at $0.7 \mathrm{~Hz}$ was marked by an initial cellular hyperpolarization in the cortical cell simultaneous with a silence in the RE cells and a depth-EEG positive wave. $B$. Traces were superimposed centered on the peak negativities from the depth EEG, and show the simultaneity between the depth-EEG positive waves, the hyperpolarization in the cortical cell, and the silent firing in RE cells during the oscillatory period. C, Numbers at the left of the depthEEG traces indicate the corresponding cycles in the raw data in $A$. The firing of the cortical cell jittered around the time zero by as much as 70 msec (compare 1 and 2 with 3 and 8 ), although the transition from hyperpolarizing to depolarizing phases of the oscillation occurred in phase. The RE cell also jittered around the zero time for values up to $100 \mathrm{msec}$. 
thalamus and the latter are closing the corticothalamocortical loop. We did not attempt to record from the third thalamic cell class, local-circuit inhibitory neurons, because they do not seem to participate in global sleep oscillations. Indeed, after disconnection from RE inputs TC cells no longer display spindles and their IPSPs are arrhythmic (Steriade et al., 1985). This result, suggesting that local thalamic interneurons are not necessarily implicated in spindle oscillations, was recently confirmed (von Krosigk et al., 1993).

In the light of the present results, we propose that a general inhibitory and/or disfacilitatory mechanism is responsible for the synchronization of corticothalamic neuronal networks generating sleep rhythms. The prolonged hyperpolarizations occurring spontaneously or as a result of afferent drives would keep cells inhibited for long enough periods to overcome phase fluctuations during the oscillation. Hypothetically, the first neuronal group to escape inhibition would drive the other elements of the network into the depolarizing phase of the oscillation. The spike bursts of TC cells that follow the synchronous inhibitory period (Fig. 9) are good candidates to trigger the depolarizing phases at every cycle of the slow oscillation. However, TC spike bursts are too short lasting to sustain the prolonged depolarizing plateaus in cortical neurons (Figs. 9, 10A). Rather, the burst firing of TC cells would modulate the frequency of the depolarizing plateaus whose durations are probably sustained by intrinsic currents of cortical cells and intracortical synaptic inputs.

The synchronizing role of a general inhibitory phenomenon is supported by our data showing that cortical, TC, and RE cells return within quite narrow time windows from the hyperpolarization elicited by electrical stimulation. The similarity between evoked and spontaneous events (Figs. 3, 4) allows us to assume that the same inhibitory mechanism subserves the timing of spontaneous oscillatory activity. Another important argument for the role of inhibitory mechanisms in bringing cells to fire together is provided by the consistent observation that, after brief desynchronizations of the EEG during which cells tended to firc tonically or irregularly in the single-spike mode, the return to the oscillatory state was achieved through an initial hyperpolarization, associated with similar hyperpolarizations in simultaneously recorded neurons and with depth-positive EEG waves (Fig. 10).

As to the origin(s) of the hyperpolarizations, several possibilities have to be considered. They are discussed below.

Biphasic IPSPs, consisting of relatively short-lasting GABA $A_{A}^{-}$ mediated and longer-lasting $\mathrm{GABA}_{\mathrm{B}}$-mediated potentials, have been elicited by afferent stimuli in both cortical (Connors et al., 1988) and dorsal thalamic (Crunelli et al., 1988) neurons. In our data, the spontaneous hyperpolarizations during the slow oscillation and the evoked ones were similar in amplitude, although their time courses differed in that spontaneous hyperpolarizations were longer lasting and showed a much smoother onset. Moreover, a GABAergic genesis of the spontaneous hyperpolarization seems very unlikely for two additional reasons: (1) in the cortex, only one neuron among all recorded discharged in opposition of phase; and (2) in the thalamus, RE neurons that represent a major source of GABAergic input to TC cells oscillated in phase with them, and although no data are available as to the phase assumed by local interneurons, it seems unlikely that they would fire only at the end of each depolarizing cycle of the oscillation.

The participation of $\mathrm{Ca}^{2+}$-activated $\mathrm{K}^{+}$currents in the long- lasting hyperpolarizations is suggested by the selective suppression of this component of the slow oscillation after stimulation of the mesopontine cholinergic nuclei (Steriade et al., 1993a). The effects of the cholinergic stimulation were suppressed by systemic administration of the muscarinic antagonist scopolamine. It is known that activation of muscarinic receptors blocks the $g_{\mathrm{K}(\mathrm{Ca})}$ that causes the $I_{\mathrm{AHP}}$ in cortical cells (Schwindt et al., 1988; McCormick and Williamsom, 1989).

The cyclic hyperpolarizations of cortical and thalamic cells might also be ascribed to adenosine, released in response to synchronous activity of neurons during their depolarizing phase. Adenosine receptors are found both in the thalamus and the cortex (Lee and Reddington, 1986), and adenosine agonists diminish neuronal firing in cortical (Phillis et al., 1975; Haas and Greene, 1988) and thalamic (Kostopoulos and Phillis, 1977) cells through an increase in a $\mathrm{K}^{+}$conductance which is shared

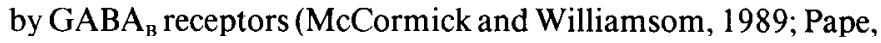
1992). In addition to its direct effects on thalamic and cortical neurons, adenosine increases the duration of slow-wave sleep (Radulovacki et al., 1982), probably due to an increase in $\mathrm{K}^{+}$ conductance of mesopontine cholinergic arousing neurons (Rainnie et al., 1994).

Still another factor accounting for the long-lasting hyperpolarizations of the slow rhythm in cortical and thalamic cells may be the sudden withdrawal of activity throughout the circuit. This would resemble the blackout periods during burst-suppression EEG patterns, in which case a few afferent volleys are sufficient to activate again the corticothalamic networks (Steriade et al., 1994a).

The slow cortical rhythm potentiates the genesis and grouping of thalamic spindles

Thalamic spindles are generated within the RE thalamic nucleus, even after the isolation of its rostral pole from dorsal thalamic and cortical inputs (Steriade et al., 1987). These experimental data are supported by modeling studies of interacting inhibitory RE cells, reciprocally coupled through fast and/or slow IPSPs (Wang and Rinzel, 1993; Destexhe et al., 1994; Golomb et al., 1994). Nevertheless, it was previously hypothesized that, in the intact brain, synaptic inputs from dorsal thalamic cells may decisively drive the conditional RE pacemaker, and thus reinforce the spindle oscillatory state (Steriade et al., 1987). Two major afferent excitatory projections to the RE nucleus are known to trigger spindles. Corticothalamic inputs potently induce spindles, much more so than prethalamic stimuli (Steriade, 1984), even when the precaution is taken to stimulate the contralateral cortex in order to avoid the antidromic invasion of thalamocortical axons (Steriade et al., 1972). As well, dorsal thalamic neurons may drive RE cells and trigger spindles in the TC-RE reciprocal projection (von Krosigk et al., 1993). The present data, showing that in many instances EPSPs elicited by internal capsule stimulation initiated the sequence of spindle waves (see Figs. 4,6), support the assumption that excitatory synaptic drives from cortical and/or dorsal thalamic cells play a role in the genesis of spindles by RE neurons. This indicates that certain RE-neuronal pools or entire sectors of the RE nucleus are capable of generating spindles even after their complete isolation (see above experimental and modeling studies), but that the full synchronization of the dorsal thalamus and consequently of the cerebral cortex may require the potentiating influences from cortico-RE and TC-RE networks.

The present data show that the depth-negative sharp EEG 
deflection, reflecting the onset of the depolarizing phase of the slow oscillation and the excitation of corticofugal neurons, powerfully drives thalamic neurons originating spindle oscillations (Fig. 4). This is supported by stimulation experiments in which corticothalamic volleys triggered spike bursts followed by spindle sequences in RE neurons. The amplitude and duration of the evoked spindle oscillation fluctuated as a function of the intensity of corticothalamic volleys (Fig. 6; see also Steriade et al., 1971).

It is worth mentioning that the sequence consisting of a depthnegative (surface-positive) sharp EEG deflection followed by spindles is termed K-complex in human sleep (Roth et al., 1956; Niedermeyer, 1993). We propose that the equivalent of human $\mathrm{K}$-complexes in cat EEGs are the sharp, depth-negative deflections giving rise to spindles (see, e.g., the top trace in Fig. 4).

One consequence of RE cell activation during the cortical slow rhythm and the ensuing spindles is the active inhibition of TC neurons. This was seen from the spontaneous firing of TC cells during natural sleep spindles (see Steriade et al., 1990) and is further reported in the following paper dealing with paroxysmal states in corticothalamic networks (Steriade and Contreras, 1994). The burst firing of TC cells occurs only at certain time intervals during sleep oscillations, so that the thalamocortical output would be relayed as an average population activity. This implies that even moderate effects on the intrinsic properties of TC cells, but affecting a large population of neurons, will have drastic effects on the oscillatory activities of thalamocortical circuits (see also Huguenard and Prince, 1994).

\section{Final remarks}

During a brain-activated state different neural elements belonging to a particular network are dynamically changing their firing rates as well as phase relations, so that an adequate number of states of the system is promptly available for computational purposes. By contrast, the low-frequency oscillations during the state of resting sleep involve large populations of neurons in the neocortex and thalamus, displaying synchronized activities with similar phase relations among heterogeneous cellular types. We propose that slow sleep oscillations produce a state of brain deafferentation by largely overwhelming the operations in multiple domains of cortical and thalamic microcircuitry devoted to different integrative processes during active behavioral states. As to the prolonged and synchronized depolarizing phases of the slow oscillation, they are hypothesized to generate cyclic spike trains that may serve to reinforce/specify the neuronal circuitry and to subserve a lengthy persistence of information acquired during wakefulncss through internally generated "nonutilitarian" excitations occurring during the state of sleep, when the interference with synaptic bombardment of external origin is absent (Steriade et al., 1993e; see also review by Kavanau, 1994).

\section{References}

Bremer F (1949) Considérations sur l'origine et la nature des "ondes" cérébrales. Electroencephalogr Clin Neurophysiol 1:177-193.

Bremer F (1958) Cerebral and cerebellar potentials. Physiol Rev 38: 357-388.

Connors BW, Malenka RC, Silva LR (1988) Two inhibitory postsynaptic potentials, and $\mathrm{GABA}_{\mathrm{A}}$ and $\mathrm{GABA}_{\mathrm{B}}$ receptor-mediated responses in neocortex of rat and cat. J Physiol (Lond) 406:443-468.

Contreras D, Curró Dossi R, Steriade M (1993) Electrophysiological properties of cat reticular thalamic neurones in vivo. J Physiol (Lond) 470:273-294.
Creutzfeldt OD, Watanabe S, Lux HD (1966a) Relations between EEG phenomena and potentials of single cortical cells. I. Evoked responses after thalamic and epicortical stimulation. Electroencephalogr Clin Neurophysiol 20:1-18.

Creutzfeldt OD, Watanabe S, Lux HD (1966b) Relations between EEG phenomena and potentials of single cortical cells. II. Spontaneous and convulsoid activity. Electroencephalogr Clin Neurophysiol 20:19-37.

Crunelli VN, Haby M, Jassik-Gerschenfeld D, Leresche N, Pirchio M (1988) $\mathrm{Cl}^{-}$and $\mathrm{K}^{+}$-dependent inhibitory postsynaptic potentials evoked by interneurones of the rat lateral geniculate nucleus. J Physiol (Lond) 399:153-176.

Curró Dossi R, Nuñez A, Steriade M (1992) Electrophysiology of a slow $(0.5-4 \mathrm{~Hz})$ intrinsic oscillation of cat thalamocortical neurones in vivo. J Physiol (Lond) 447:215-234.

Deschênes M, Paradis M, Roy JP, Steriade M (1984) Electrophysiology of neurons of lateral thalamic nuclei in cat: resting properties and burst discharges. J Neurophysiol 51:1196-1219.

Destexhe A, Contreras D, Sejnowski TJ, Steriade M (1994) A model of spindle rhythmicity in the isolated thalamic reticular nucleus. $\mathbf{J}$ Neurophysiol 72:803-818.

Domich L, Oakson G, Steriade M (1986) Thalamic burst patterns in the naturally sleeping cat: a comparison between cortically-projecting and reticularis neurones. $J$ Physiol (Lond) 379:429-450.

Glenn LL, Hada J, Roy JP, Deschênes M, Steriade M (1982) Anterograde tracer and field potential analysis of the neocortical layer I projection from nucleus ventralis medialis of the thalamus in cat. Neuroscience 7:1861-1877.

Golomb D, Wang XJ, Rinzel J (1994) Synchronization properties of spindle oscillations in a thalamic reticular nucleus model. $J$ Neurophysiol 72:1109-1126.

Haas HL, Greene RW (1988) Endogenous adenosine inhibits hippocampal CAl neurones: further evidence from extra- and intracellular recording. Arch Pharmacol 337:561-565.

Huguenard JR, Prince DA (1994) Intrathalamic rhythmicity studied in vitro: nominal $\mathrm{T}$ current modulation causes robust anti-oscillatory effects. J Neurosci 14:5485-5502.

Jahnsen H, Llinás R (1984) Electrophysiological properties of guineapig thalamic neurones: an in vitro study. J Physiol (Lond) 349:205226.

Jones EG (1985) The thalamus. New York: Plenum.

Kavanau JL (1994) Sleep and dynamic stabilization of neural circuitry: a review and synthesis. Behav Brain Res, in press.

Klee MR, Offenloch K, Tigges H (1965) Cross-correlation of electroencephalographic potentials and slow membrane transients. Science 147:519-521.

Kostopoulos GK, Phillis JW (1977) Purinergic depression of neurons in different areas of the rat brain. Exp Neurol 55:719-724.

Lee KS, Redington M (1986) Autoradiographic evidence for multiple CNS binding sites for adenosine derivatives. Neuroscience 19:535549 .

Leresche N, Lightowler S, Soltesz I, Jassik-Gerschenfeld D, Crunelli V (1991) Low-frequency oscillatory activities intrinsic to rat and cat thalamocortical cells. J Physiol (Lond) 441:155-174.

Llinás RR (1988) The intrinsic electrophysiological properties of mammalian neurons: insights into central nervous system function. Science 242:1654-1664.

Lopes da Silva F (1991) Neural mechanisms underlying brain waves: from neural membranes to networks. Electroencephalogr Clin Neurophysiol 79:81-93.

McCormick DA, Pape HC (1990) Properties of a hyperpolarizationactivated cation current and its role in rhythmic oscillation in thalamic relay neurones. J Physiol (Lond) 431:291-318.

McCormick DA, Williamsom A (1989) Convergence and divergence of neurotransmitter action in human cerebral cortex. Proc Natl Acad Sci USA 86:8098-8102.

McCormick DA, Connors BW, Lighthall JW, Prince DA (1985) Comparative electrophysiology of pyramidal and sparsely spiny stellate neurons of the neocortex. J Neurophysiol 54:782-806.

Morison RS, Bassett DL (1945) Electrical activity of the thalamus and basal ganglia in decorticate cats. J Neurophysiol 8:309-314.

Mulle C, Madariaga A, Deschênes M (1986) Morphology and electrophysiological properties of reticularis thalami neurons in cat: in vivo study of a thalamic pacemaker. J Neurosci 6:2134-2145.

Niedermeyer E (1993) Sleep and EEG. In: Electroencephalography: basic principles, clinical applications, and related fields (Niedermeyer 
E, Lopes da Silva F, eds), pp 153-166. Baltimore: Williams and Wilkins.

Nuñez A, Amzica F, Steriade M (1993) Electrophysiology of cat association cortical cells in vivo: intrinsic properties and synaptic responses. J Neurophysiol 70:418-430.

Pape HC (1992) Adenosine promotes burst activity in guinea-pig geniculocortical neurones through two different ionic mechanisms. J Physiol (Lond) 447:729-733.

Pedley TA, Traub RD (1990) Physiological basis of the EEG. In Current practice of clinical electroencephalography (Daly DD, Pedley TA, eds), pp 107-137. New York: Raven.

Phillis JW, Kostopoulos GK, Limacher JJ (1975) A potent depressant action of adenine derivatives on cerebral cortical neurons. Eur J Pharmacol 30:125-129.

Radulovacki M, Miletich RS, Green RD (1982) N ${ }^{\circ}$ (L-phenylisopropyl) adenosine (L-PIA) increases slow-wave sleep $\left(\mathbf{S}_{2}\right)$ and decreases wakefulness in rats. Brain Res 246:178-180.

Rainnie DG, Grunze HCR, McCarley RW, Greene RW (1994) Adenosine inhibition of mesopontine cholinergic neurons: implications for EEG arousal. Science 263:689-692.

Roth M, Shaw J, Green J (1956) The form, voltage distribution and physiological significance of the K complex. Electroencephalogr Clin Neurophysiol 8:385-402.

Schwindt PC, Spain JW, Foehring RC, Chubb MC, Crill WE (1988) Slow conductances in neurons from cat sensorimotor cortex in vitro and their role in slow excitability changes. J Neurophysiol 59:450 467

Steriade M (1984) The excitatory-inhibitory response sequence in thalamic and neocortical cells: state-related changes and regulatory systems. In: Dynamic aspects of neocortical function (Edelman GM, Gall WE, Cowan WM, eds), pp 107-157. New York: Wiley.

Steriade M (1993) Cellular substrates of brain rhythms. In: Electroencephalography: basic principles, clinical applications, and related fields (Niedermeyer E, Lopes da Silva F, eds), pp 27-62. Baltimore: Williams and Wilkins.

Steriade M, Contreras D (1995) Relations between cortical and thalamic cellular events during transition from sleep patterns to paroxysmal activity. J Neurosci 15:623-642.

Steriade M, Apostol V, Oakson G (1971) Control of unitary activities in cerebellothalamic pathway during wakefulness and synchronized sleep. J Neurophysiol 34:389-413.

Steriade M, Wyzinski P, Apostol V (1972) Corticofugal projections governing rhythmic thalamic activity. In: Corticothalamic projections and sensorimotor activities (Frigyesi TL, Rinvik E, Yahr MD, eds), pp 221-272. New York: Raven.
Steriade M, Deschênes M, Domich L, Mulle C (1985) Abolition of spindle oscillations in thalamic neurons disconnected from nucleus reticularis thalami. J Neurophysiol 54:1473-1497.

Steriade M, Domich L, Oakson G (1986) Reticularis thalami neurons revisited: activity changes during shifts in states of vigilance. J Neurosci 6:68-81.

Steriade M, Domich L, Oakson G, Deschênes M (1987) The deafferented reticularis thalamic nucleus generates spindle rhythmicity. $J$ Neurophysiol 57:260-273.

Steriade M, Jones EG, Llinás RR (1990) Thalamic oscillations and signaling. New York: Wiley.

Steriade M, Curró Dossi K, Nuñez A (1991) Network modulation of a slow intrinsic oscillation of cat thalamocortical neurons implicated in sleep delta waves: cortically induced synchronization and brainstem cholinergic suppression. J Neurosci 11:3200-3217.

Steriade M, Amzica F, Nuñez A (1993a) Cholinergic and noradrenergic modulation of the slow $(\sim 0.3 \mathrm{~Hz})$ oscillation in neocortical cells. J Neurophysiol 70:1385-1400.

Steriade M, McCormick DA, Sejnowski TJ (1993b) Thalamocortical oscillations in the sleeping and aroused brain. Science 262:679-685.

Steriade M, Nuñez A, Amzica F (1993c) A novel slow $(<1 \mathrm{~Hz})$ oscillation of neocortical neurons in vivo: depolarizing and hyperpolarizing components. J Neurosci 13:3252-3265.

Steriade M, Nuñez A, Amzica F (1993d) Intracellular analysis of relations between the slow $(<1 \mathrm{~Hz})$ neocortical oscillation and other sleep rhythms of the electroencephalogram. J Neurosci 13:3266-3283.

Steriade M, Contreras D, Curró Dossi R, Nuñez A (1993e) The slow $(<1 \mathrm{~Hz})$ oscillation in reticular thalamic and thalamocortical neurons: scenario of sleep rhythm generation in interacting thalamic and neocortical networks. J Neurosci 13:3284-3299.

Steriade M, Amzica F, Contreras D (1994a) Cortical and thalamic cellular correlates of electroencephalographic burst-suppression. Electroencephalogr Clin Neurophysiol 90:1-16.

Steriade M, Contreras D, Amzica F (1994b) Synchronized sleep oscillations and their paroxysmal developments. Trends Neurosci 17 199-208.

Villablanca J (1974) Role of the thalamus in sleep control: sleepwakefulness studies in chronic diencephalic and athalamic cats. In: Basic sleep mechanisms (Petre-Quadens O, Schlag J, eds), pp 51-81. New York: Academic.

Von Krosigk M, Bal T, McCormick DA (1993) Cellular mechanisms of a synchronized oscillation in the thalamus. Science 261:361-364.

Wang XJ, Rinzel J (1993) Spindle rhythmicity in the reticularis thalami nucleus-synchronization among inhibitory neurons. Neuroscience 53:899-904. 